\title{
The SARAL/AltiKa mission: A step forward to the future of altimetry
}

\author{
Verron Jacques ${ }^{1}$, Bonnefond Pascal ${ }^{2}$, Andersen Ole ${ }^{3}$, Ardhuin Fabrice ${ }^{4}$, Bergé-Nguyen Muriel ${ }^{5}$, \\ Bhowmick Suchandra ${ }^{6}$, Blumstein Denis ${ }^{5,7}$, Boy François ${ }^{7}$, Brodeau Laurent ${ }^{8}$, \\ Crétaux Jean-François ${ }^{5,7}$, Dabat Mei Ling ${ }^{5}$, Dibarboure Gérald ${ }^{7}$, Fleury Sara ${ }^{5}$, Garnier Florent ${ }^{5}$, \\ Gourdeau Lionel ${ }^{5}$, Marks Karen ${ }^{9}$, Queruel Nadège ${ }^{8}$, Sandwell David ${ }^{10}$, Smith Walter H.F. ${ }^{9}$, \\ Zaron Ed ${ }^{11}$
}

\footnotetext{
${ }^{1}$ Institut des Géosciences de l'Environnement, CNRS, CS 40700, 38058 Grenoble Cedex 9, France

2 Observatoire de Paris, SYRTE, 77 avenue Denfert Rochereau, 75014 Paris, France

3 DTU SPACE, National Space Institute, Technical University of Denmark, Elektrovej, 2800 Kgs.

Lyngby, Denmark

${ }^{4}$ LOPS, IFREMER, CS 10070, 29280 Plouzané, France

${ }^{5}$ LEGOS, 14 Avenue Edouard Belin, 31400 Toulouse, France

${ }^{6}$ ISRO, Oceanic Sciences Division, Space Applications Centre, Ambawadi Vistar P.O., Ahmedabad, 380015, India

${ }^{7}$ CNES, 18 Avenue Edouard Belin, 31400 Toulouse, France

8 OCEAN NEXT, 90 chemin du Moulin, 38660 La Terrasse, France

9 Laboratory for Satellite Altimetry, NOAA, 5830 University Research Court, College Park, MD 20740, Maryland, USA

${ }^{10}$ Scripps Inst. of Oceanography, 8622 Kennel Way, La Jolla, CA 92037, California, USA

${ }^{11}$ Department of Civil and Environmental Engineering, Portland State University, P.O. Box 751

Portland, OR 97207-0751, Oregon, USA
}

\begin{abstract}
:
The CNES/ISRO altimetric satellite SARAL/AltiKa was launched in February 2013 and since then has provided useful data for various scientific and operational applications in oceanography, hydrology, cryospheric sciences and geodesy. However, a Reaction Wheel problem forced relaxation of the repeatability constraint on the satellite's orbit, which has been drifting slowly since July 2016. Beyond the expected contributions of this mission and its very good integration into the objectives of the constellation of altimetric satellites, it has become more and more apparent that specific contributions and innovations related to the main specification of SARAL/AltiKa, that is to say the use of the Ka-band, have clearly emerged. The advantages of the Ka-band are in short the reduction of ionosphere effects, the smaller footprint, the better horizontal resolution and the higher vertical resolution. A drawback of the Ka-band is the attenuation due to water/water vapor in case of rain and the resulting loss of data. The main objective of this paper is to highlight the specific advances of the Ka-band in different scientific and technical fields and to show why they are promising for the future and open the way to several missions or mission projects. Although unplanned initially, the fine coverage of the Drifting Phase brings some interesting openings especially for geodesy and hydrology applications.
\end{abstract}


Keywords : satellite, altimetry, Ka-band 


\section{Introduction}

The SARAL ( "Satellite with ARgos and ALtiKa" also meaning "Easy" in Sanskrit) mission is jointly conducted by the Indian Space Agency (ISRO) and the French Space Agency (CNES). SARAL was launched on February 25, 2013. Calibration and validation investigations have shown that the quality of the data meets the expectations and initial mission requirements as discussed for example in Bonnefond et al. (2018). Data have been delivered to users in a very rapid manner. They are available on EUMETSAT, CMEMS and CNES servers. The quality of all products was in line with mission requirements. Many scientific investigations have been undertaken and a large part of the scientific community has quickly seized the opportunity offered by these data.

In 2015, SARAL/AltiKa exhibited an increasing need to reduce the stress on its Reaction Wheels in order to extend the mission beyond the nominal lifetime of the satellite. ISRO and CNES eventually decided that the best strategy was to stop all orbit control maneuvers and to let the altitude decay naturally. SARAL/AltiKa left its repetitive orbit to 
begin a new phase named "Drifting Phase" (DP) starting July 4, 2016 (Dibarboure et al. 2018). Data processing and data latency were unchanged. From this date, SARAL satellite has flown free of station keeping maneuvers. The repetitive ground track is no longer maintained and with the natural decay of the orbit, the ground track is slowly drifting. In short, this new orbit configuration has required some adjustment for users, particularly in hydrology, given the need to adapt the algorithms. On the contrary, some other uses profit from this new orbital configuration.

The SARAL/AltiKa's main scientific objectives were to provide data to oceanographers to improve knowledge and understanding of the ocean mesoscale variability. These scientific objectives regarding mesoscale ocean dynamics come under different aspects: observations, theoretical analyses, modeling and data assimilation. Climate studies are also concerned by SARAL/AltiKa not only through the improved access to the sea-level measurements but also by contributing to understand the role of mesoscale features on the climate variability. Coastal oceanography was also directly interested by the SARAL/AltiKa data as well as many downstream applications including operational oceanography. SARAL/AltiKa's other objectives include inland waters (lakes, rivers, enclosed seas), monitoring of sea-level changes, polar oceans, wave and wind fields, continental and sea ice, etc. Since the beginning of the mission, the SARAL/AltiKa Ka-band altimetric mission has taken a full position in the altimetric satellite constellation that has been built over years providing a major push to oceanographic sciences. The scientific results are exemplified by the special issue dedicated to SARAL/AltiKa (Verron and Picot 2015) and many other papers.

The purpose of the present paper is to go further in these directions by highlighting how the specific features of SARAL/AltiKa has allowed new openings both in terms of data, science and applications and to discuss how a Ka-band satellite such as SARAL/AltiKa opens the way to future satellite projects. The paper is written by first quickly recalling two aspects of the SARAL/AltiKa mission: the technological continuity and its gapfiller role. Indeed, SARAL/AltiKa has been designed in a technological continuity with other altimetry satellites, building on a true maturity of altimetry technology: it is a remarkable dimension of this mission whose main aspects are quickly recalled in Section 2. But SARAL/AltiKa also aimed at being a gapfiller between Envisat and Sentinel-3A: we briefly recall how SARAL/AltiKa fulfilled this objective in Section 3.

But the essential purpose of this paper is to discuss how SARAL/AltiKa has been a real driver of innovation. In Section 4, we discuss on the case of the resolution of the oceanic mesoscales and the openings towards the Surface Water Ocean Topography Mission (SWOT) (e.g. Durand et al. 2010 \& Biancamaria et al. 2016) and of the capability of SARAL/AltiKa to access to the snow depth and then to the openings towards the CRISTAL mission project. In Section 5, the role of SARAL/AltiKa as a demonstrator for the SKIM and for the SMASH mission projects is evoked. Section 6 discusses more specifically of the Drifting Phase and the openings that are offered in geodesy and for lakes observations. Conclusions are provided in Section 7.

\section{Technological continuity}

It is useful to remember that SARAL/AltiKa relies on a great maturity of the altimetry technology and a long history (Vincent et al. 2006). The SARAL satellite is composed of a spacecraft bus developed by the Indian Space Agency (ISRO), and a payload developed by the French Space Agency (CNES). As its full name indicates, two missions are onboard the SARAL satellite: The AltiKa altimeter component - of interest here - and ARGOS-3. The altimeter payload includes first the AltiKa Altimeter-Radiometer in Ka-band, a DORIS system for precise orbit determination (POD), and a Laser Retro-reflector Array instrument used for precise calibration of other POD instruments (Steunou et al. 2015). The altimeter shares the antenna with a bi-frequency radiometer required to correct the altimeter range for the wet troposphere path delay. AltiKa is a nadir-looking altimeter in line with Poseidon-3 on-board Jason-3 and other existing altimeters, but operates in a single frequency band, the Ka-band.

Ka-band offers a number of advantages and has some possible drawbacks. Ka-band is much less affected by the ionosphere than Ku-band (Steunou et al. 2015). It is this reduced ionosphere effects in Ka-band that makes it possible to use a mono-frequency altimeter and implicitly removes the noise of the ionosphere derived from dual-frequency for other missions. The Ka-band high frequency (35.75 GHz, to be compared to $13.5 \mathrm{GHz}$ on Jason-2/3) leads to a smaller footprint ( $8 \mathrm{~km}$ diameter, to be compared to $20 \mathrm{~km}$ on Jason-2/3 and to $15 \mathrm{~km}$ for Envisat) and to a better horizontal resolution. Ka-band allows to use a larger bandwidth (480 MHz to be compared to $320 \mathrm{MHz}$ on Jason-2/3). This 480 $\mathrm{MHz}$ bandwidth provides a high vertical resolution $(0.3 \mathrm{~m})$ which is better with respect to other altimeters. The higher Pulse Repetition Frequency ( $4 \mathrm{kHz}$ to be compared to $2 \mathrm{kHz}$ on Jason-2/3) permits a decorrelation time of sea echoes at Ka-band shorter than at Ku-band, then allowing a better along-track sampling ( $40 \mathrm{~Hz} v \mathrm{vs} .20 \mathrm{~Hz}$ ). This makes possible 
to increase significantly the number of independent echoes per second compared with Ku-band altimeters. This low ionospheric attenuation can even be considered as negligible, except for some exceptional ionospheric situations. It discards the need for a dual-frequency altimeter. Ka-band provides a better estimation of sea surface roughness than at Ku-band (see e.g. Bhowmick et al. 2015 \& Abdalla 2015). The $8 \mathrm{~mm}$ wavelength in Ka-band is better suited to describing the detailed slopes of the sea surface and gives a more accurate measurement of the backscatter coefficient over calm or moderate seas, thus leading to a noise reduction of a factor of two compared to Jason-class altimeters for wave heights greater than $1 \mathrm{~m}$. With Ka-band, there is a lower radar penetration of snow and ice: penetration of snowpack is less than $3 \mathrm{~cm}$ for snow on sea ice and $1 \mathrm{~m}$ for continental ice, around ten times less than for Ku-band. The altimetric observation and height restitution thus correspond to a thin subsurface layer.

A possible drawback of Ka-band was that the attenuation due to water or water vapor in the troposphere might affect Ka-band pulses in case of rain and increase significantly the rate of missing data for strong rain rates. In fact, this was not found to be true, thanks in particular to a fine tuning of the data processing (more especially the flagging algorithm as discussed in particular by Tournadre et al. 2015), and rain had little influence on data availability and quality.

\section{A gapfiller between Envisat and Sentinel-3A}

The SARAL/AltiKa orbit is almost polar ( $98.55^{\circ}$ of inclination), sunsynchronous and with a 35-day repeat cycle. These orbit characteristics of SARAL/AltiKa were chosen to be the same as Envisat. The practical objectives were to continue the time series and to benefit from the existing mean sea surface thanks to long term mean sea profiles from ERS-1/2 and Envisat. As a consequence, the SARAL/AltiKa mission was considered as a "gap filler" between Envisat (lost in April 2012) and Sentinel-3A (launched in February 2016). This gap filler objective is almost fully fulfilled: because of the late launch of SARAL/AltiKa compared to the loss of Envisat there is however a gap of 8 months.

In particular, we can notice the key contributions of SARAL/AltiKa to the Data Unification and Altimeter Combination System (DUACS) products on the corresponding period. The DUACS production system is used for the operational production of sea level products for the Marine (CMEMS) and Climate (C3S) services of the EU Copernicus program, for the processing of the Sentinel-3 products on behalf of EUMETSAT and for the production of demonstration and pre-operational products on behalf of CNES. As discussed in Dibarboure et al. (2018) and Verron et al. (2018) for example, SARAL/AltiKa contributed to around 45\% of the input data to DUACS during the period ranging from Spring 2013 to Nov. 2016. Even in the recent period since Nov. 2016, including after the launch of Sentinel-3, SARAL/AltiKa contributes to something between 25 and $30 \%$ of the altimeter data flow.

\section{Some innovations from SARAL/AltiKa and openings for ocean, snow and ice observations}

The main objective of this paper is to discuss how much SARAL/AltiKa was and is innovative and what routes are opening for the future thanks the pioneer role of SARAL/AltiKa. Two emblematic examples are discussed below, the case of the oceans and the one of snow and ice.

\subsection{An improved access to the fine scales of the ocean and a playground for the SWOT mission}

The first and most obvious of these routes is that opened by the good horizontal resolution and low noise of the SARAL/AltiKa measurement of the Sea Surface Height (SSH) for oceanography. This allows better access to oceanic mesoscales and their variability. And it is no coincidence that the SWOT mission will be launched in 2021 using the Ka-band for its KaRin main radar instrument.

Let us comment a little more about access to the mesoscales. This is also a SARAL/AltiKa's main scientific objective to improve our knowledge of the ocean mesoscale variability, mainly associated to eddies, meandering currents, fronts, filaments and squirts. The mesoscale variability refers to ocean signals with space scales of $50 \mathrm{~km}$ to $500 \mathrm{~km}$ and time scales from a few days to a few months.

Technological advances in all of the recent satellite altimeter missions have improved their signal-to-noise ratio, allowing us to observe finer-scale ocean processes with along-track altimeter data. Using $1 \mathrm{~Hz}$ data, Vergara et al. (2019) revisited global SSH wavenumber spectra from recent altimetric missions. With specific editing for SARAL/AltiKa, they show the dramatic improvement in SSH error levels achieved by Sentinel-3A, which is around $40 \%$ 
better than SARAL/AltiKa error level (itself 30\% better than Jason-2), whatever distinct seasonal and geographical variations related to local oceanic/atmospheric conditions such as Significant Wave Height (SWH), rain cells, wind streaks and ocean slicks. Their results confirm the globally-averaged SSH wavenumber spectra from the different missions described in Verron et al. (2018) (their Figure 1) when analyzing high resolution data (20/40 Hz). For the Jason-SARAL/AltiKa class altimeters, this statistical estimate of the altimetric noise and the observable scales are largely constraint by a spectral hump in the $10-40 \mathrm{~km}$ wavelength range due to the inhomogeneities in the ocean surface, as well as atmospheric events that does not exist for a SAR altimeter such as Sentinel-3A. Dibarboure et al. (2014) shows that oceanography users interested in small-scale SSH signals can mitigate the hump corruption by using better editing and post-processing algorithms. They test two simple editing procedures on the $20 \mathrm{~Hz}$ Jason data: a running standard deviation threshold and a nonlinear iterative editing filter. Both methods exhibit a substantial mitigation of the hump. The shape of SSH spectra for the shorter wavelength change drastically, especially for the SARAL mission with an error level below the Sentinel-3A error level as shown by the globally-averaged SSH wavenumber spectra from the different missions described in Bonnefond et al. (2018) (their Figure 12). The data-editing step is an important phase of altimeter data processing because it determines the quantity and quality of the measurements ultimately available that directly impact the estimation of SSH wavenumber spectra. Using $1 \mathrm{~Hz}$ SARAL/AltiKa data, Gourdeau et al. (2017) propose two new editing procedures: a specific median filter applied on the SSH data set (MAD filter), and a clustering editing procedure based on a subset of GDR parameters that improve the data-editing step especially in coastal areas.

Here we show that a careful data editing on $1 \mathrm{~Hz}$ data to filter out outliers modifies the shape of the SSH spectra. Such editing criteria are tested in open-ocean by the use of a MAD filter. Spectra are representative of a $1500 \times 1500$ $\mathrm{km}$ square box chosen south of New Caledonia in an area of strong mesoscale variability (Figure 1). The difference in the editing procedure by comparison with the standard procedure recommended in the User Handbook does not change the spectral characteristic for the Jason-2/3 and Sentinel-3A mission. But the effect is particularly significant for wavelength finer than $90 \mathrm{~km}$ when using SARAL/AltiKa data even if the MAD filter rejects only $4 \%$ of the data. One explanation is the reduced footprint and the sensitivity of the Ka-band to the atmospheric conditions compared to the Ku-band. If the estimation of the mesoscale spectral slope is similar whatever the satellite missions with a $\mathrm{k}^{-3.5}$ slope characteristic of a SQG dynamics, the error level (estimated by fitting a straight line to the Sea Level Anomaly (SLA) spectra for wavelengths smaller than $30 \mathrm{~km}$ ) is drastically reduced to $1.3 \mathrm{~cm}$ for the SARAL/AltiKa mission when using the MAD filter. The noise level of SARAL/AltiKa is lower compared to Jason-2 and Sentinel-3A as already illustrated at global scale by Bonnefond et al. (2018) with the effect to observe 20\% (10\%) smaller features than Jason-2 (Sentinel-3). SARAL/AltiKa can observe wavelengths of $70 \mathrm{~km}$, whereas Jason-2 only allow to observe wavelengths of $90 \mathrm{~km}$, and $80 \mathrm{~km}$ for Sentinel-3A.

Then, at this stage, the benefit of the Ka-band is clearly illustrated when looking at the finest scales. If working on the raw $40 \mathrm{~Hz}$ data is the best way to reduce the hump effect that affects wavelength up to $100 \mathrm{~km}$ (Dibarboure et al. 2014), a more easier editing procedure based on $1 \mathrm{~Hz}$ data provide similar results based on a spectral approach. In general, we find that the latest generation altimetry satellites are consistent among themselves with respect to the spectral behavior at the largest scales. For the smaller scales, the level of error and effective resolution appears to be better with SARAL/AltiKa.

The mesoscale resolution capability of present generation altimeters is improving our understanding of the contribution of mesoscale processes on the ocean circulation. As such, SARAL/AltiKa observations are particularly well suited to assess the ability of high-resolution ocean models to resolve these mesoscale processes (see for example Le Sommer et al. 2018 on the status of current ocean models). Meanwhile, it is the same numerical models that are presently used to prepare the SWOT mission, both when it comes to simulating the submesoscale altimetric signal that SWOT will actually "see" and to generate synthetic data to prepare post-processing. SARAL/AltiKa therefore plays an important, indirect, yet critical, role in the preparation of upcoming high-resolution altimetry missions like SWOT.

Here we illustrate how SARAL data are used to perform a spectral comparison of the simulated ocean surface state from a submesoscale-permitting twin-experiment performed with eNATL60 to observations. eNATL60 is a basinscale North Atlantic configuration of the NEMO model (https://www.nemo-ocean.eu/) at unprecedented horizontal and vertical resolutions $\left(1 / 60^{\circ}\right.$ and 300 levels respectively) (Figure 2). Technically, the horizontal grid resolution of eNATL60 varies from 0.8 up to $1.6 \mathrm{~km}$ and the effective resolution has been shown to be about $10 \mathrm{~km}$. These simulations were supported through an allocation from the EU PRACE program (www.prace-ri.eu/). SARAL/AltiKa data is used for spectral evaluations of the SSH generated by these simulations and in particular for assessing the 
energy contribution of the internal tide to the SSH signal. As shown in Figure 3, the model behavior is close to SARAL/AltiKa for large scales down to $\sim 80 \mathrm{~km}$. The inclusion of tidal forces leads to a significant energy increase of the SSH signal at smaller scales. The energy level is much more pronounced in Summer, because of the strong stratification, more conducive to the generation and spread of the internal tide. At these fine scales, the cascade of energy approaches a slope in $\mathrm{k}^{-2}$, peculiar to a flow regime dominated by wave turbulence. Still at these fine scales, the altimetry signal measured by SARAL/AltiKa (and other current satellites) is obscured by the noise and therefore does not allow a direct confrontation with the model. At scales larger than typically $100 \mathrm{~km}$, on the other hand, the flow is balanced, and in agreement with the QG theory, the cascade of energy follows a slope in $\mathrm{k}^{-5}$, in excellent agreement with SARAL/AltiKa.

Combining the knowledge of a realistic virtual surface state of the ocean at the kilometer scale resulting from these simulations to the knowledge of an observed surface state from SARAL/AltiKa data, will allow to start unravelling some aspects of the mesoscale dynamics with regard to the tidal effects and internal waves, the seasonality effect, regional aspects, etc ... All this for the purpose of improving the knowledge of ocean surface dynamics that will allow better use and interpretation of future SWOT data.

Note that in the frame of the Copernicus extension beyond 2030, it is envisaged to replace nadir altimeters for Sentinel-3 by wide-swath altimeters. A study named WiSA (Wide-Swath Altimetry) is currently in phase A in collaboration between CNES and ESA, and SARAL/AltiKa technology and data are also strongly contributing to the design of such mission.

Finally it is found that the transition to the SARAL-DP has no significant drawback on the mesoscale sampling capability. Dibarboure et al. (2012) demonstrated that it could be possible to find geodetic orbits that were compatible with mesoscale monitoring: this was achieved by including so-called "orbit sub-cycles" that maximize the ocean mesoscale sampling over a period of 15 to 20 days. But this study was carried out in the context of a well-maintained altitude, and the mesoscale sampling properties of altitude-decaying orbits had not been studied so far. DP demonstrated that it is possible for altimeter missions to keep a good mesoscale sampling for years even if their altitude is not actively maintained and even if it decays due to the atmospheric drag. Indeed, Dibarboure et al. (2018) report that the orbit sub-cycles evolve in slow and continuous way over a few kilometers of altitude. Because the SARAL orbit is affected by a moderate atmospheric drag (altitude loss of approximately $20 \mathrm{~cm} /$ day), the satellite will remain in an altitude range with mesoscale-compatible orbit sub-cycles for many years. Figure 4 from Dibarboure et al. (2018) explains why the SARAL-DP was initiated approximately $1 \mathrm{~km}$ above the ERS/Envisat orbit. Indeed, even accounting for the altitude loss, the sampling pattern of DP remains controlled by 13, 16 and 19-day sub-cycles, i.e. a good combination for mesoscale for 6 years or more. The quality of mesoscale observation is measured using the decorrelation between adjoining SARAL/AltiKa tracks. When the altimeter tracks are very close from one another (e.g. distance shorter than the decorrelation scales of ocean mesoscale), they provide duplicate mesoscale content. In turn, other regions of the ocean are poorly sampled which results in an overall degraded observation capability (see Dibarboure et al. 2012).

\subsection{A Unique Tool for Sea Ice and Snow Cover Observation and a key step for the CRISTAL mission}

The observations of sea ice and snow is a primary importance for the climate. Whereas the global warming can be characterized by many parameters, one of the most demonstrative is the reduction of the Arctic Sea Ice area in Summer that has lost about $13 \%$ of its surface with regard to the previous decade. This phenomenon is mainly explained by the differences of albedos between the sea ice, its snow cover and the surrounding ocean, which are respectively of about $0.5,0.9$ and 0.1 : under the influence of the global warming, the ice tends to melt, offering a larger surface of ice-free ocean that absorbs 2 to 9 times more of the solar energy than ice. In its turn this extra heat accelerates the ice melting. This positive feedback explains the Arctic amplification of the global warming. The Arctic sea ice is both a key witness and an actor of the global climate, although clearly there are strong regional effects.

Arctic and Austral sea ice has been mainly survey with optical, thermic and radiometric satellite images. They have allowed monitoring of the sea ice extent and concentration daily since the late Seventies. These observations have largely contributed to improve sea ice models and are now frequently used to constraint such models for shortterm forecasts of the sea ice extent (e.g. Screen \& Simmonds 2010). Nevertheless numerous publications have recently demonstrated that these forecasts can be largely improved when assimilating sea ice thickness (SIT) observation (e.g. Xie et al. 2018) or more precisely, the sea ice freeboard, which is a proxy of the SIT. This can be intuitively understood as the thinnest is the ice the more fragile it is to thermo-mechanical stresses (heat, waves, currents, ...). 
The first attempts to measure sea ice freeboard have used ERS-2's altimeter but with large uncertainties (Peacok and Laxon, 2004). The method consists of measuring the height differences between the ice and the surrounding water in the cracks of the ice (see Figure 5). This approach has been deeply improved thanks to the first SAR altimeter on board CryoSat, which produced several sea ice freeboard products (Guerreiro et al. 2016). Using such product, Blockley and Peterson (2018) have demonstrated the ability to extend the sea ice forecast range from a few weeks to a few months.

But snow is still a missing parameter. The conversion of the sea ice freeboard $\left(h_{i}\right)$ into SIT basically consists in applying the hydrostatic equilibrium equation:

$$
S I T=\frac{h_{i} \rho_{w}}{\rho_{w}-\rho_{i}}
$$

$\rho_{i}$ and $\rho_{w}$ are respectively the density of ice and water. But this equation must be corrected to account for the presence of snow on the ice pack for two reasons: i) the load induced by snow, and ii) the decrease in the speed of propagation of the Ku-band radar wave in snow (see Figure 5). Then Eq. 1 must be re-written as follows:

$$
S I T=\frac{h_{i} \rho_{w}+(1+\alpha) h_{s} \rho_{s}}{\rho_{w}-\rho_{i}}
$$

where $h_{s}$ is the snow depth, $\rho_{s}$ the snow density and $\alpha$ the decrease of speed propagation in snow. The snow density is about $30 \%$ of the water density and the speed reduction $\alpha$ is between $20 \%$ to $25 \%$. While the average snow depth is probably slightly higher than the freeboard in the Arctic, their ratio is much more significant in Antarctica. It implies that the term related to the ice and the term related to the snow in the numerator of Eq. 2 are of the same order of magnitude. In other words, the snow depth is nearly as important as the freeboard to retrieve SIT.

Nevertheless, while the measurement of freeboard has made great progress, the same cannot be said for the measurement of snow depth that still remains largely unknown. For now all the SIT products derived from altimetry use the Warren 99 climatology that has been established from 1954 to 1991 Arctic expeditions, i.e. before the sensible effects of global warming. The only adaptation of this climatology consists in dividing by two the snow depth over the first year ice in order to take into account its reduced lifespan. This solution is known as the "modified Warren climatology" (W99m).

SARAL/AltiKa is the first satellite to give some access to snow depth observations. With regard to the Ku-band, the Ka-band frequency does not penetrate so much the snow. Several studies have explored this potential to retrieve the snow depth ( Armitage \& Ridout 2015, Guerreiro et al. 2016). While the first study concludes that 50\% of the Ka-band penetrates the snow, the correction of the surface roughness in the second study has resulted in remarkable correlations between $\mathrm{Ka} / \mathrm{Ku}$ satellite altimeters and Operation Ice Bridge snow radar airborne measurements (see Figure 6).

From the difference of the freeboards, computed respectively with SARAL/AltiKa and CryoSat (using the pLRM mode), snow depth maps were established for the seven colder months of the Arctic (October-April) and the six colder months of the Antarctic (May-October) over the period 2013-2017 and up to $81.5^{\circ} \mathrm{N} / \mathrm{S}$.

This opens the way toward improved SIT observations. New SIT monthly maps have been computed from this Altimetric Snow Depth (ASD) product, and the freeboard obtained with CryoSat (using the SAR and SARIN mode). In order to estimate the impact of the snow depth solution, we have substituted this snow solution with W99m's and CNRM's snow solutions. The results presented Figure 7 confirm the hypothesis deduced from Eq. 2. The SIT products over the Arctic and the Antarctic, using the ASD, will be soon available (http://ctoh.legos.obs-mip.fr/). Whereas the sea ice extent encountered a drastic reduction, the only radar altimeter that covers the Arctic Ocean, and more generally the Polar Regions, is CryoSat that is already 9 years old.

All these works and first of all, the SARAL/AltiKa findings, justify the consideration of a new mission project, CRISTAL, using Ku- and Ka- band together. CRISTAL is one of the 6 High Priority Candidate Missions (HPCM) of the Copernicus Sentinel Expansion program. The first priorities of this polar mission is to survey the sea ice, its snow cover and the land ice, and its main objectives are to support the maritime operations in the polar oceans and to better understand the climate processes. This mission will be equipped with the first $\mathrm{Ka} / \mathrm{Ku} \mathrm{SAR} / \mathrm{SARin}$ altimeter, and with an increased band-width $(500 \mathrm{MHz})$ to improve the vertical resolution. The Ku-band insures the continuity of the long series of $\mathrm{Ku}$ altimetric survey of the solid and liquid water over the planet, and the Ka-band brings a clear innovation 
to measure the snow depth. Contrarily to the results presented above, the Ka and the Ku measurements will be synchronous and from a same reference platform, allowing simultaneous measurements of the heights of ice, of snow and of waters, with unprecedented precisions. So the CRISTAL mission, with the quality of the SAR/SARin technology, will be able to extend the measurements of seas, lakes, rivers, permafrost, glaciers and ice caps heights up to $88^{\circ} \mathrm{N} / \mathrm{S}$ in near-real time, and also the snow depth on the sea ice and probably on frozen land. Although it is already known, through SARAL/CryoSat-2 comparisons, that the $\mathrm{Ka} / \mathrm{Ku}$ difference provides a good proxy for snow depth, further studies are needed to validate and determine possible corrections to this approach based on the characteristics of the snow (depth, density, grain sizes, salinity, number of layers, etc.) and its support (ice, sea ice, land). For that purpose, SARAL/AltiKa remains an essential and unique tool to accomplish the preparation of CRISTAL. Its extension should allow further analyses of the penetration of $\mathrm{Ka}$ and $\mathrm{Ku}$ bands in snow, in particular through comparisons with the new $\mathrm{Ka} / \mathrm{Ku}$ radars on board the CryoVex aircraft, with the IceSat-2 lidar and with in-situ measurements.

\section{SARAL/AltiKa : a demonstrator for future Ka-band missions}

\subsection{A demonstrator for the SKIM mission}

SKIM is one of the two candidate satellite missions under development for ESA Earth Explorer 9 (Ardhuin et al. 2019). The Sea surface KInematics Multiscale monitoring (SKIM) satellite mission is designed to explore ocean surface currents and waves. This includes tropical currents, notably the poorly known patterns of divergence and their impact on the ocean heat budget, and monitoring of the emerging Arctic up to $82.5^{\circ} \mathrm{N}$. SKIM will also make unprecedented direct measurements of strong currents, from boundary currents to the Antarctic circumpolar current, and their interaction with ocean waves with expected impacts on air-sea fluxes and extreme waves. Horizontal velocity components will be obtained with an accuracy better than $7 \mathrm{~cm} / \mathrm{s}$ for horizontal wavelengths larger than $80 \mathrm{~km}$ and time resolutions larger than 15 days, with a mean revisit time of 4 days for of $99 \%$ of the global oceans. This will provide unique and innovative measurements that will further our understanding of the transports in the upper ocean layer, permanently distributing heat, carbon, plankton, and plastics. SKIM will also benefit from co-located measurements of water vapor, rain rate, sea ice concentration, and wind vectors provided by the European operational satellite MetOp-SG(B), allowing many joint analyses.

For the first time, SKIM will directly measure the ocean surface current vector from space. The main instrument on SKIM is a Ka-band conically scanning, multi-beam Doppler radar. The main innovation is the combination of rotating beams similar to SWIM on CFOSAT (Hauser et al. 2017), here with incidence angles $\mathrm{i}=0^{\circ}$ (nadir), $6^{\circ}$ and $12^{\circ}$, with a Doppler capability that will measure the surface velocity vector and ocean wave spectra across a $320 \mathrm{~km}$ swath. The well-proven Doppler pulse-pair technique will give a surface drift velocity representative of the top meter of the ocean, after subtracting a large wave-induced contribution. The velocity is given by the phase difference of consecutive pulses (pulse-pairs) transmitted at a frequency of $32 \mathrm{kHz}$. This high pulse repetition frequency guarantees a high coherence between consecutive pulses. Ka-band was chosen for its high precision compared to Ku-band (pulse-pair technique precision is three time higher in Ka-band). On the other hand, one of the major concerns of using Ka-band is its sensitivity to atmospheric conditions. Same concerns were shared during the development of the SARAL/AltiKa mission, but now, future Ka-band missions can be built using SARAL/AltiKa measurements and experience. Lessons learned show the data loss over ocean is lower than anticipated $(<0.1 \%)$ and the signal-to-noise ratio is higher than the preflight expected value thanks to margins taken in the altimeter link budget (Steunou et al. 2015). Despite the very low number of lost data, the presence of atmospheric liquid water impacts the altimeter waveform shape. In a same way, SKIM radar measurements will be polluted. SARAL/AltiKa measurements has been used to evaluate the global impact. Figure 8 shows the percentage of SARAL/AltiKa measurements impacted by rain events thanks to the use of the matching pursuit algorithm (Tournadre et al. 2009). Flagging strategy and algorithms have been designed on SKIM based on this experience.

In addition, accurate SKIM measurements of the geophysical surface velocity require a very accurate knowledge of the platform pointing error. Besides this, an apparent skew-pointing of the radar beam can also be caused by a non-homogeneous distribution, within the observed ocean scene, of the normalized radar cross section (NRCS) $\sigma_{0}$. This error is directly proportional to the azimuthal $\sigma_{0}$ gradients within the footprint. SARAL/AltiKa measurements is used to evaluate the amplitude of this error, at global scales. $\sigma_{0}$ map at $12^{\circ}$ incidence (SKIM, Figure 9b) has been extrapolated from SARAL/AltiKa $\sigma_{0}$ map (Figure 9a) using equations from (Nouguier et al. 2016). Then, $\sigma_{0}$ 
gradients has been computed (Figure 9c) and the error was estimated and the analysis confirmed the agreement with performances expectations.

In case of selection in the Earth Explorer 9 ESA program, SKIM or its avatars will keep on learning from SARAL/AltiKa experience to consolidate the mission performances, data processing and instrument design.

\subsection{A demonstrator for the SMASH mission}

SMASH (SMall Altimetry Satellites for Hydrology) is a satellite altimetry constellation aimed at providing daily water levels of rivers, lakes and other inland water bodies with an end-to-end accuracy of $10 \mathrm{~cm}$ for which a feasibility investigation is presently supported by CNES (Blumstein et al. 2019).

Indeed, the monitoring of water resources at the global scale is already a major challenge whose importance will increase in the next years. Continental waters are essential components of the water, energy and carbon cycles. The rivers and lakes water levels are identified as essential climate variables by the Global Climate Observing System (GCOS) which recommends daily measurements of these variables. Traditionally, this information was provided by gauge data. However, the availability of these in situ measurements is very heterogeneous and is declining (Global Runoff Data Centre, GDRC). For the last twenty years, numerous research teams have demonstrated that measurements from space altimeters could be used to mitigate this lack of in situ measurements even if these instruments where mainly designed for measurements over the oceans (Birkett 1995, 1998, Crétaux et al. 2006, 2015, Frappart et al. 2015, Hossain et al. 2014). However, all the historic and current altimetry missions, based on repeat track orbits with cycle durations of 10 days (TOPEX/Poseidon Jason-2/3), 27 days (Sentinel-3), 35 days (ERS-2, Envisat, SARAL/AltiKa) and more (CryoSat) cannot provide these measurements daily (Tourian et al. 2016, Boergens et al. 2017). As the performance of altimetry missions applied to inland water surfaces improves constantly, the next frontier is to increase the frequency of temporal revisit.

The SMASH mission is a proposal to reach this goal. It is very complementary to the Wide Swath altimetry missions like SWOT and WiSA which provide almost complete spatial coverage at a lower temporal frequency. The mission is based on a constellation of small satellites each carrying a Ka-band altimeter.

The optimization of the payload definition was based on the precious experience gained from the analysis of in-flight measurements provided by the AltiKa altimeter: both the standard $40 \mathrm{~Hz}$ data and the so-called individual echoes (IE). These IE are the raw outputs of the altimeter and 96 of them are incoherently summed on-board to provide a $40 \mathrm{~Hz}$ echo (or waveform). In order to save downlink bandwidth, only the $40 \mathrm{~Hz}$ echoes are nominally transmitted to the ground. However, occasionally, a sequence of one second of successive IE is transmitted, this is similar to the Envisat bursts (Roca et al. 2007). A first analysis of IE data was described in Quartly and Passaro (2018) for the ocean. Here, we report an analysis using a method adapted to inland waters radar returns which are very different from the returns observed over the oceans. Specifically, the returns over inland waters are very peaky and can often be accurately modeled (e.g. Abileah et al. 2017) as the Point Target Response (PTR) of the instrument which is, in theory, a squared cardinal sine $\left(\operatorname{sinc}^{2}\right)$ for SARAL/AltiKa.

We analyzed one pass of SARAL/AltiKa data over the Salar de Uyuni. The Salar de Uyuni on the Altiplano of southwestern Bolivia is a $9.600 \mathrm{~km}^{2}$ salt lake, the largest salt flat in the world. Its surface is expansive, flat, smooth, and is a specular reflector, making it an ideal satellite altimeter target. Contrary to these previous studies we choosed a period when it was fully inundated on the 28th of January 2019, making its surface even more flat and smooth (very much like an almost perfect mirror). Indeed we were much more interested in the intrinsic noise of the instrument rather than on its absolute calibration.

Figure 10, resulting from this Sala de Uyuni investigation, is highly instructive. First, the noise of the height retrieved from the IE at $4 \mathrm{kHz}$ is in this case very low (around $6 \mathrm{~mm}$ RMSE). This means that we get a very precise evaluation at a spatial sampling of around $2 \mathrm{~m}$. Furthermore, the curve of heights retrieved from the $40 \mathrm{~Hz}$ waveform is very close from it. Second, we have here a clear demonstration that, on this kind of peaky waveforms, the ice1 retracking algorithm can be outperformed by algorithms using physical models of the waveform, here a simple PTR model, and that the accuracy improvement can be significant (ice 1 RMSE $5 \mathrm{~cm}$, sinc ${ }^{2}$ retracking $5 \mathrm{~mm}$ ). The acquisition of this type of measurements over a wide diversity of inland waterbodies (rivers, lakes, floodplains all of various sizes and shapes) sampled over the world is ongoing. The results of the analysis of this dataset will be an important factor to guide the design choices in order to reduce the costs while maintaining the performances of the mission. We believe this will be a key factor in the demonstration of the feasibility of the SMASH payload. 


\section{Ka-band and the Drifting Phase}

The main consequence of the DP was that the SARAL subsatellite track rapidly drifted away from the historical ground track formerly used by the ERS and the Envisat satellites since the Nineties. Sandwell et al. (2014) have shown that using a drifting ground track could be extremely useful for the marine geodesy community: the unprecedented precision of SARAL/AltiKa could help resolve uncharted sea mounts and sea floor topography. Indeed, improving marine geodesy products requires a so-called "geodetic altimeter sampling", i.e., a sampling pattern where the subsatellite tracks over a long period (e.g., one year) create a very dense grid with a resolution of $8 \mathrm{~km}$ or less. In general, this is achieved by keeping precisely the satellite on a so-called "geodetic orbit", i.e., an orbit with a very long exact repeat cycle (e.g. Jason-1 Geodetic-Mission, or Jason-2 Long Repeat Orbit (LRO) phase). In contrast, for SARAL-DP, there is not an exact repeat because the orbit altitude decays continuously. Yet the geodetic sampling of SARAL-DP is still naturally dense, albeit somewhat random. An efficient metric to characterize the quality of the geodetic grid is to look at the histogram of the distance between adjoining equator crossings for ascending or descending altimeter tracks. To illustrate, Jason-2 LRO is currently sampling a $4 \mathrm{~km}$ resolution grid over a period of 2 years (mid-2017 to mid-2019). The LRO grid is also built from two 8-km interleaved grids of one year each. The Jason-2 LRO grid is currently incomplete after only 1.5 years, which results in the histogram of Figure 11b. This histogram has 2 peaks: one at $4 \mathrm{~km}$ where the final grid has been sampled, and one at $8-\mathrm{km}$ grid for equator nodes that will be acquired in the coming months. Using the same metric for SARAL after 2.5 years of drifting phase yields Figure 11a. Because of the random nature of the DP orbit, the histogram is different from Figure 11b: instead of 2 very narrow peaks associated with a controlled geodetic orbit, the histogram of SARAL-DP is continuous with an average of $3.2 \mathrm{~km}$, with many grid nodes less than $2 \mathrm{~km}$ from one another, but many other with $5 \mathrm{~km}$ or more (this number would be 0 if the orbit was controlled like Jason-2 LRO). In December 2018, approximately $75 \%$ of the 4-km geodetic grid has been effectively sampled. This is less than the $100 \%$ that would have been collected with a controlled orbit, but that is still a very large and precious geodetic dataset. A possible Jason-2 mission extension up to 2021 would allow to almost fill a $2 \mathrm{~km}$ grid but only for latitude below $66^{\circ}$ while SARAL/AltiKa will provide complementary information for high latitudes.

\subsection{Comparisons of SWH ans SLA measurements and Predicting Cyclones in both SARAL/AltiKa phases}

As said earlier, SARAL/AltiKa went for a DP operation from July 2016. Thus to begin applications it was wise to find out how the observation of SARAL changed in such new mode. Thus individual 3 months (October-December 2016) of data from SARAL/AltiKa in DP was analysed and compared to 3 months (July-September 2013) of SARAL/AltiKa data in the nominal exact repeat orbit mode (ERM).

Figure 12 shows the 3 monthly average of SWH data from these two modes. One thing was noteworthy from this exercise is on a monthly scale the availability of data in DP is much more than the ERM mode. To test the quality of the data, a global validation was carried out using NDBC buoy data particularly for two geophysical products i.e. wind and wave. It was seen that both the wind and waves are of very high quality in DP. In the similar way the Jason-2 SLA has been inter-compared with the SARAL SLA in two phases.

The left panel in Figure 13 shows the comparison of the SWH with global buoy data in October 2016 when SARAL was in DP and October 2013 when SARAL was in ERM mode respectively. The right panel on the other hand shows the comparison of SLA for same months using the Jason-2 SLA from AVISO.

Albeit one can say that statistically SWH in DP looks like a mild improvement upon ERM mode. But this is not the case since the number of observation increases in DP as compared to ERM mode resulting to a better statistic. But one can safely conclude that DP data is equally good and high quality observations from SARAL as ERM mode is. The real impact of the change to DP is evident in the OGDR of the SLA which shows a mildly lowered correlation and mild increase in RMSE and Bias. Thus the DP SWH and Wind are equally high quality and useable as ERM mode data. However, the SSHA may need little bit of correction in successive levels (IGDR and GDR).

Thus to look into the suitability of application of the DP model data in oceanography we randomly select two cyclones which occurred during SARAL being in ERM and DP respectively. These are Phailin (October 4, 2013 October 14, 2013) and Vardah (December 9, 2016 - December 19, 2016). The former is a Category-5 cyclone with 3 min sustainable wind speed of $230 \mathrm{~km} / \mathrm{h}$ and the other one is Category- 1 cyclone with the same as $150 \mathrm{~km} / \mathrm{h}$, but both look heavy toll on Indian subcontinent in terms of fatality. SARAL/AltiKa happened to monitor both closely. Figure 14 shows the SARAL/AltiKa observing waves during Phailin and Vardah on 11th October 2013 and 11th December 2016 respectively. Very clearly SARAL /AltiKa in both the cases were able to peak up the intense impact of cyclone 
over the ocean. The east Indian Coastal Current (EICC) was found to become intense during the cyclone cases for example in case of Vardah the EICC on 1st December 2016 prior to occurrence of the cyclone and on 11th December 2016 when it was at its best status has been shown in left and right panels of Figure 15. Even in its drifting phase, SARAL/AltiKa was able to provide valuable information that have led to accurate capture of the change of EICC during cyclone Vardah.

\subsection{Tides and the SARAL/AltiKa Drifting Phase}

SLA data acquired during the SARAL/AltiKa drifting orbit mission phase have been useful for evaluating newlydeveloped ocean tide models. An early example of this is the evaluation of a baroclinic tide model in Ray and Zaron (2016). Tide models such as FES (Lyard et al., 2006), DTU (Cheng and Andersen, 2011), and GOT (Ray, 2013) incorporate nearly all available altimeter data from missions in the so-called reference orbits originally occupied by the TOPEX/Poseidon and ERS-1/2 missions. Thus, the measurements from the drifting orbit occupied by SARAL/AltiKa are extremely valuable because they are from locations not routinely sampled, and the precision of these measurements is advantageous in distinguishing the small differences among tide models (e.g., Stammer et al, 2014). For example, comparisons of the variance reduction of the latest FES2014 tide model (Carrere et al, 2016), compared with the older FES2004 model (Lyard et al. 2006), validate the newer model and exhibit its improvements at small scales near the coastline (Figure 16). Note that the spacing of the reference mission ground tracks is generally quite large compared to the scales of the tides near the coast, and the existing tide gauge network is otherwise not able to globally validate the improvements in tide models near the coast (Andersen et al. 2006).

\subsection{SARAL/AltiKa for a refined observation of lakes}

Lake water level can be measured over long period of time using constellation of radar altimeters. It has been used in a considerable number of studies ( e.g. Crétaux et al. 2016). However, in contrast to large lakes or rivers, onboard altimeters also may have difficulties to track the real surface of the water body when it is narrow or located in region with rough topography, or in case where several water bodies at different altitudes are located close to each others. It is particularly the case in boreal regions like the northern Canada, Alaska or Siberia, but also in mountaineous areas. In such situation, the tracker simply does not always acquire the measurements due to bad a priori information on the definition and adjustment of the tracking window of the instruments. To solve this question, recently, a new tracking mode has been implemented onboard the two missions, Jason-3 and Sentinel-3A. It is based on a priori onboard database with near real time information on the position of the satellite (thanks to the DORIS/Diode navigator (Jayles et al. 2010) and a database including a pseudo Digital Elevation Model (DEM) with a priori height of the water bodies (lakes and rivers). The two tracking mode are called respectively Close Loop (CL) and Open Loop (OL). The target's predicted distance is calculated directly by the altimeter, combining altitude data from DORIS/Diode with the altitude from the DEM recorded in the altimeter's onboard memory. Recent results have proved that OL mode has allowed tracking continuously more than $90 \%$ of potential lakes compared to only $50 \%$ when the tracking mode is the CL with Jason-3. However the number of potential lakes is much larger for the current missions like Sentinel-3A and Sentinel-3B.

Hopefully in 2021, SWOT will be able to measure water height of about 8 millions of lakes worldwide with a revisit of 21 days and an expected accuracy of $10 \mathrm{~cm}$ for lakes larger than $1 \mathrm{~km}^{2}$. In order to perform an optimal use of the interferometer, it is also necessary to use a priori lake database with several information: reference contour and height of each lake (Rodriguez 2015). For SWOT which measures differences of phases, a priori DEM is necessary in order to solve for ambiguity, which is at the range of 5-10 m in the near range and more like $60 \mathrm{~m}$ in the far range. Since the accuracy of a priori height for onboard DEM (for nadir altimeter and for SWOT) is on the order of magnitude of 5 to $10 \mathrm{~m}$, the main issue is to obtain satellite data from various instruments in order to cover the maximum of lakes worldwide. This is evident that over the 8 millions of lakes that will be surveyed using SWOT it is practically impossible to obtain a priori height from current nadir altimeters for the totality of them, but geodetic missions are well designed to measure reference height of a very high number of targets. Jason-2 and SARAL/AltiKa are current missions both candidates for this purpose. However, Jason-2 does not cover high latitude region while SARAL/AltiKa does. Since the beginning of the SARAL-DP about 3 years of data have been acquired. It therefore now allows overpassing a very high number of lakes, in particular in the boreal region where the majority of lakes are located. For a region located on the east bank of the Hudson Bay, we have done a simulation of the potential of 


\begin{tabular}{|l||c|c|c|}
\hline & Total & $\begin{array}{c}\text { Nominal orbit } \\
\text { (Number/Percentage) }\end{array}$ & $\begin{array}{c}\text { Drifting Phase } \\
\text { (Number/Percentage) }\end{array}$ \\
\hline GLWD & 130 & $100 / 77 \%$ & $130 / 100 \%$ \\
All lakes & 6000 & $1725 / 28 \%$ & $4500 / 75 \%$ \\
\hline
\end{tabular}

TABLE 1: Coverage of worldwide lakes by SARAL/AltiKa during the nominal orbit phase and the SARAL-Drifting Phase by reference to the present Global Lakes and Wetlands Database.

SARAL/AltiKa to provide reference height of the lakes present in this region. A single pass is presumably enough to reach this objective.

Figure 17 shows the coverage of SARAL/AltiKa over the nominal mission (from cycle 1 to 35 ) and over the DP until now. The largest lakes are also represented. They are released in the Global Lakes and Wetlands Database (GLWD, https://www.worldwildlife.org/pages/global-lakes-and-wetlands-database) in the form of polygons of the lake's contours. Over this region we have computed the number of lakes present in the GLWD, the number that are overpassed by the nominal orbit and the number that are overpassed during the DP. To fill Table 1 we have counted the number of lakes for which at least one valid measurement (without error's flag in the GDRs) is acquired within the polygons defining the lake contour. For lakes within the GLWD, it was simply done using the existing lake polygons, while for smaller lakes, we have done manual inspection for the final counting. With the DP orbit all of the lakes included within the GLWD are now covered using the DP orbit since it was only $77 \%$ with the nominal orbit. If now we look at all lakes bigger than $1 \mathrm{~km}^{2}$, that therefore are for most of them not included into GLWD, then the gain is much higher. The total number of lakes included in the zone, which has served as example, increased from $28 \%$ of the totality using nominal orbit to $75 \%$ using the DP orbit. This result suggests therefore that a longer period of DP orbit with SARAL/AltiKa of few months will likely be enough to cover almost $100 \%$ of lakes bigger than $1 \mathrm{~km}^{2}$. This represents approximately 300,000 to 400,000 lakes worldwide according to Verpooter et al. (2014) for which a least a reference height could be estimated using only SARAL/AltiKa. In order to consolidate the computation, the use of data from other missions has already started. In particular we have calculated reference height of about 6000 lakes and reservoirs worldwide using only Cryosat mission. It will serve for cross validation with the SARAL/AltiKa data over the same lake dataset. Results are summarized in Table 1.

The statement on the SARAL/AltiKa potential to provide height's reference for lakes larger than $1 \mathrm{~km}^{2}$ is valid in favorable environment conditions. It has been shown for example in Arsen et al. (2015) that a realistic threshold of approximately $10 \mathrm{~km}^{2}$ is more likely valid in mountainous conditions, and with the aim to perform highly accurate time series of water height variations. For the objective of performing height reference with precision of about 4-5 $\mathrm{m}$ (which is needed for SWOT a priori database) we assessed in Table 1 that this is achievable in flat regions like the Canadian plains where the biggest world density of small lakes is observed. In mountainous region, this is likely a too optimistic assessment and potentially, only lakes bigger than $10 \mathrm{~km}^{2}$ would be observable by SARAL/AltiKa .

\subsection{SARAL/AltiKa for a refined description of the geoid and of the MSS}

The value of satellite altimetry for geodesy lies in the combination of uniform mapping at high spatial density and the range precision of the individual sea surface height observations, and SARAL/AltiKa is an excellent altimeter for resolving short-wavelength features in the geoid/gravity and mean sea surface (MSS).

The investigations by Smith (2015) showed that the range precision of SARAL/AltiKa is roughly 2 times more precise than Envisat due to its more beam-limited waveform shape and its higher pulse repetition frequency of $4 \mathrm{kHz}$ (vs. $2 \mathrm{kHz}$ for Envisat). The range precision is 2.5 times more precise than older geodetic mission data from Geosat and ERS-1. Compared with other altimeters currently flying (Jason-2 and Cryosat), the range precision is roughly twice as precise as Jason-2 and even 50\% better than the Cryosat SAR altimetry. Zhang and Sandwell (2017) even demonstrated that SARAL/AltiKa benefits from the 2-pass retracking.

Since July 2016 then, the SARAL-DP leads to a ground track pattern will be more uneven (e.g. Figure 18 over the Hawaii area). Other geodetic missions are maintained in controlled geodetic missions with typical $8 \mathrm{~km}$ ground track spacing. The uneven drifting ground track pattern of SARAL/AltiKa is in principle a "downside" as it limits the spatial resolution of the recovered gravity and MSS to twice the largest ground track spacing (up to $20 \mathrm{~km}$ as of 2019). However, by merging the SARAL/AltiKa data with the regular sampled geodetic mission of Jason-1/2 or Cryosat, this 
is counter-acted such that the full potential and full usage of the high range precision can be gained in a systematic way.

Detection of seamount and bathymetry mapping are and will be a key usage of the SARAL-DP data. Earlier generation of altimeter technology could map all seamounts $2 \mathrm{~km}$ and taller than $2 \mathrm{~km}$, but there might be as many as 50,000 seamounts between 1-2 km tall that were not yet found. Smith (2015) used single cycles of SARAL/AltiKa $40 \mathrm{~Hz}$ sea surface height data to identify seamounts as small as $1.35 \mathrm{~km}$ tall from the initial exact repeat mission (consequently limited by the roughly $70 \mathrm{~km}$ cross track spacing). A further development of this was presented by Marks and Smith (2016). Here "stacked" repeat cycles of 32 repeat (nearly 3 years) of $40 \mathrm{~Hz}$ SARAL/AltiKa data profiles over selected areas improved the resolution of small seamount signals and lowered the noise. The noise variance decreases with an increase in the number of cycles stacked and was below $2 \mathrm{~cm}$ when 12 or more repeat cycles were stacked. Seamounts smaller than $\sim 720 \mathrm{~m}$ tall could easily be identified in the stacked profiles, and a seamounts $500 \mathrm{~m}$ tall was perceptible. Coherence analyses between geoid height and topography shows that full wavelengths down to $\sim 10 \mathrm{~km}$ are being resolved with SARAL/AltiKa. Marks and Smith (2018) applied a seamount detection filter to stacked SARAL/AltiKa sea surface profiles globally, revealing over 75,000 possible seamounts (Figure 19).

It was possible to assign proxy heights to 4824 of the possible seamounts that were located over multibeam surveys, by subtracting regional SRTM30 depths from the multibeam depths. These proxy heights followed a Poisson statistical distribution similar to that which fit acoustic bathymetry profiles over seamounts (Figure 20). This model suggests at least $84 \%$ of the possible seamounts are less than $2 \mathrm{~km}$ tall. Employing the stacking method on repeat cycle data from other modern satellites may further augment the global seamount census, particularly for seamount heights less than $2 \mathrm{~km}$ tall.

Another important virtue of SARAL/AltiKa for geodesy is the smaller footprint illuminated on the sea surface. The smaller footprint is particularly important for geodetic purposes in coastal- and sea ice-contaminated regions, as fewer sea surface height observations are corrupted by the presence of land or ice inside the footprint The Ka-band altimeter has a slightly smaller footprint than other conventional altimeters operating at Ku-band when wave heights are small (see Figure 9 and Equations 10 \& 11 in Smith (2015)). Within the Geomed-2 project (Barzaghi et al. 2018) to derive an improved geoid of the Mediterranean Sea we investigated the importance of geodetic mission data from different geodetic missions in complex coastal regions.

The histogram of geoid residuals to EGM2008 from one year of Jason-1 (Figure 21 left picture) and from 3 years of SARAL/AltiKa (Figure 21 right picture) clearly demonstrate the superior data coverage with SARAL/AltiKa in coastal regions due to the smaller footprint. This is particularly important for recovering the marine gravity field and MSS in coastal and Arctic regions. In Arctic regions sea-ice effects are similar to coastal effects in disturbing the waveform inside the footprint.

\section{Conclusion}

In this paper, the specificities of Ka-band altimetry and of SARAL/AltiKa which is the first satellite using it, have been reminded. We have tried to show from this - by developing each of the main aspects - how it is possible to project into the future towards new planned or proposed satellite missions (e.g. SWOT, CRISTAL, SKIM and SMASH, which are all in Ka-band).

For the oceans, SARAL/AltiKa provides an improved resolution and a better accuracy of the SSH signal especially at the mesoscales. Assuming appropriate editing, the along-track SSH spatial resolution SARAL/AltiKa provides resolution better than Jason-2/3 missions and even than Sentinel-3A. Note that coastal oceanography directly benefits of the better discrimination in transition zones as well as this improved resolution of the measurements. These refined measurements in the regional and coastal areas is of major relevance to societal applications. Until the first high resolution altimetry observations from the SWOT mission are available, SARAL/AltiKa is the satellite capable of providing altimetry observations at the best resolution. In this context, SARAL/AltiKa data has the potential to play a key and forerunner role in the preparation, interpretation and understanding of future SWOT data.

For inland waters, SARAL/AltiKa definitely improves the quality of hydrology products derived from satellite altimetry. Especially for water level time series over lakes and rivers, SARAL/AltiKa dramatically improved the measurements due to its smaller footprint and its higher pulse repetition frequency. SARAL/AltiKa allows the access 
to smaller rivers and lakes that are not accessible with standard altimeters. During the Drifting Phase, SARAL/AltiKa appears to open the way for better observing lakes on various size in various regions such as Canada or Siberia. All of this provide a strong technological and scientific foundation for the SMASH proposal for inland waters observations, but also for better designing the SWOT mission (e.g. the DEM).

For high latitudes, ice-covered regions, the lesser radar penetration of snow by SARAL/AltiKa is beneficial for various types of measurements and especially for a better discrimination between snow, ice and water. The difference between $\mathrm{Ka}$ and $\mathrm{Ku}$-band height provides a good proxy of snow depth above sea ice that is a limitation to estimate ice thickness. Sea ice and ice sheet measurements are a major issue for climate monitoring. As for inland waters applications, ice applications gave evidence of the key importance of continuous observations along the same repeat orbit, as was possible with ERS-2, Envisat and SARAL/AltiKa (during the nominal phase). This is used to develop the CRISTAL project using a dual Ku-Ka band system.

Ka-band clearly brings some opportunities to understand Ku-band better. This is an evidence in the previously mentioned case of ice and snow measurements. But this is probably true also for other domains (e.g. wave-currents interaction studies).

For geodesy, it appears that AltiKa is an excellent altimeter for resolving short-wavelength geoid anomalies. In the Drifting Phase, the resulting dataset will be a boon to marine geophysics, bathymetric estimation, and seamount mapping. Seamount size-frequency distribution models suggest that there may be as many as $10^{5}$ seamounts between 1 and $2 \mathrm{~km}$ in height that are uncharted and were not detected by previous Ku-band altimeters. After the full completion of the Drifting Phase, SARAL/AltiKa will surely find some of these and brings a major improvement in the Mean Sea Surface definition very useful for all altimetric missions.

Clearly, SARAL/AltiKa is an altimetric satellite mission that opens more than previously the doors of interdisciplinarity. Indeed, the extended capabilities that are offered by the Ka-band allow to open even more widely some new frontiers of altimetry such as coastal oceanography, cryospheric sciences, hydrology, beyond the traditional scope of the open ocean investigations. It is therefore very significant to note that an initially oceanography-dedicated satellite like SARAL/AltiKa opens the way - thanks to the Ka-band - to satellite projects not only in oceanography like SWOT and SKIM but also in glaciology (CRISTAL), in hydrology (SWOT, SMASH) or even in geodetic directions.

The use of the Ka-band had initially been seen as problematic because of the important limitations hypothesized in rain situations. The SARAL/AltiKa mission was launched despite this constraint, taking a certain risk in this respect but also preventing as much as possible the difficulties by appropriate technological adjustments. Reality shows that these limitations were largely overestimated. The abundance of Ka-band satellite projects today demonstrates a posteriori the value of some technological risk-taking for the benefit of scientific and operational applications.

Beyond the scientific impacts mentioned previously, the experience of the SARAL/AltiKa Drifting Phase is of interest for other satellite missions. SARAL/AltiKa has demonstrated the benefits of this DP strategy: reducing the number of maneuvers has effectively extended the satellite lifetime as expected, and the DP orbit provides an enhanced sampling capability of ocean mesoscale, as well as precious measurements to improve marine geodesy references fields (e.g., bathymetry, geoid or mean sea surface). More generally, the strategy developed for SARAL/AltiKa can be used for any other altimeter (e.g., Jason-3 or Sentinel-3), for instance if the satellite maneuvering capability is limited by onboard aging anomalies (Dibarboure et al. 2018). This strategy could also be used to minimize satellite operations, or to reduce the amount of fuel needed during the mission's lifetime and then applied to mission/constellation for which the maintenance effort is highly limited (i.e. nanosatellites).

\section{References}

[1] Abdalla S. (2015). SARAL/AltiKa Wind and Wave Products: Monitoring, Validation and Assimilation, Marine Geodesy, 38, 365-380, DOI: 10.1080/01490419.2014.1001049

[2] Abileah R., A. Scozzari and S. Vignudelli (2017). "Envisat RA-2 Individual Echoes: A Unique Dataset for a Better Understanding of Inland Water Altimetry Potentialities". Remote Sens. 9, 605; doi:10.3390/rs9060605

[3] Andersen, O. B., G. D. Egbert, S. Y. Erofeeva, and R. D. Ray (2006). "Mapping nonlinear shallow-water tides: a look at the past and future". Ocean Dynamics 56, 416-429.

[4] Ardhuin, F, Brandt, P, Gaultier, L, Donlon, CJ, Battaglia, A, Boy, F, Casal, T, Chapron, B, Collard, F, Cravatte, S, Delouis, J-M, Witte, ED, Dibarboure, G, Engen, G, Johnsen, H, Lique, C, López-Dekker, P, Maes, C, Martin, A, Marie, L, Menemenlis, D, Nouguier, F, Peureux, C, Rampal, P, Ressler, G, Rio, M-H, Rommen, B, Shutler, JD, Suess, M, Tsamados, M, van Sebille, E, Ubelmann, C, Vorst, MVD, Stammer, D. (2019). "SKIM, a candidate satellite mission exploring global ocean currents and waves". Frontiers in Marine Science 6, doi 10.3389/fmars.2019.00209 
[5] Armitage, T. W. K., \& Ridout, A. L. ( 2015), Arctic sea ice freeboard from AltiKa and comparison with CryoSat?2 and Operation IceBridge, Geophys. Res. Lett., 42, 6724Đ 6731, doi:10.1002/2015GL064823.

[6] Arsen, A., Crétaux, J. F., \& Abarca del Rio, R. (2015). Use of SARAL/AltiKa over mountainous lakes, intercomparison with Envisat mission. Marine Geodesy, 38, 534-548

[7] Barzaghi R., D. Carrion, G. S. Vergos, et al. (2018). "GEOMED2: High-Resolution Geoid of the Mediterranean". In: Freymueller J., SĞnchez L. (eds) International Symposium on Advancing Geodesy in a Changing World. International Association of Geodesy Symposia, vol 149., p43-49, Springer Verlag, Heidelberg.

[8] Biancamaria, S., Lettenmaier, D. P., \& Pavelsky, T. M. (2016). The SWOT Mission and Its Capabilities for Land Hydrology. Surveys in Geophysics, 37(2), 307-337.

[9] Birkett, C. M. (1995). The contribution of TOPEX/POSEIDON to the global monitoring of climatically sensitive lakes. Journal of Geophysical Research : Oceans, 100, 25179Đ25204, doi :10.1029/95JC02125.

[10] Birkett, C. M. (1998). Contribution of the TOPEX NASA radar altimeter to the global monitoring of large rivers and wetlands. Water Resources Research, 34, 1223Đ1239, doi :10.1029/98WR00124.

[11] Blockley, E. W., and Peterson, K. A. (2018). "Improving Met Office seasonal predictions of Arctic sea ice using assimilation of CryoSat-2 thickness". The Cryosphere 12(11), 3419-3438.

[12] Blumstein D., A. Guérin, A. Lamy et al., (2019): SMASH: A Constellation of Small Altimetry Satellites Dedicated to Hydrology. Presented at the 6th Workshop on Advanced RF Sensors and Remote Sensing Instruments, ARSIÕ19 \& 4th Ka-band Earth Observation Radar Missions Workshop, KEO'19, ESA/ESTEC, Noordwijk, The Netherlands

[13] Boergens, E.; Buhl, S.; Dettmering, D.; Kl\$ppelberg, C.; Seitz, F. (2017). Combination of multi-mission 743 altimetry data along the Mekong River with spatio-temporal kriging. J. Geodesy, 91, 519-534, 744 doi:10.1007/s00190-016-0980-z.

[14] Bonnefond P., Verron J.;, Aublanc J., Babu K.N., Bergé-Nguyen M., Cancet M., Chaudhary A., Crétaux J.F., Frappart F., Haines B.J., Laurain O., Olivier A., Poisson J.C., Prandi P., Sharma R., Thibaut P., Watson C. (2018). "The benefits of the Ka-band as evidenced from the SARAL/AltiKa altimetric mission: quality assessment and specificities of AltiKa data". Remote Sens., 10(1), 83; https://doi.org/10.3390/rs10010083.

[15] Bhowmick S. A., R. Modi, K. G. Sandhya, M. Seemanth, T. M. Balakrishnan Nair, Raj Kumar \& R. Sharma (2015). Analysis of SARAL/AltiKa Wind and Wave over Indian Ocean and its Real-time Application in Wave Forecasting System at ISRO, Marine Geodesy, 38, 396-408, DOI: 10.1080/01490419.2015.1006380

[16] Busker, T., Roo, A. D., Gelati, E., Schwatke, C., Adamovic, M., Bisselink, B., ... \& Cottam, A. (2019). A global lake and reservoir volume analysis using a surface water dataset and satellite altimetry. Hydrology and Earth System Sciences, 23(2), 669-690.

[17] Carrere L., F. Lyard, M. Cancet, A. Guillot, N. Picot: FES 2014, a new tidal model - Validation results and perspectives for improvements, Presentation to ESA Living Planet Conference, Prague 2016.

[18] Cheng, Y., \& O. B. Andersen (2011). Multimission empirical ocean tide modeling for shallow waters and polar seas, J. Geophys. Res., 116, C11001

[19] Crétaux J-F and C. Birkett, (2006) lake studies from satellite altimetry, C R Geoscience, Vol 338, 14-15, 1098-1112, doi: 10.1016/J.cre.2006.08.002

[20] Crétaux J-F., Biancamaria S., Arsen A., Bergé-Nguyen M., and Becker M., (2015) Global surveys of reservoirs and lakes from satellites and regional application to the Syrdarya river basin, Environmental Research Letter, 10,1, AN: 015002, 2015, DOI: 10.1088/17489326/10/1/015002

[21] Crétaux, JF., Abarca-del-Rio, R., Bergé-Nguyen, M. et al. (Surv Geophys, (2016). "Lake Volume Monitoring from Space". Surveys in Geophysics, 2016, 37 (2), 269-305 //doi.org/10.1007/s10712-016-9362-6

[22] Dibarboure, G., Schaeffer, P., Escudier, P., Pujol, M.-I., Legeais, J.F., Faugère, Y.;, Morrow, R., Willis, J.K., Lambin, J., Berthias, J.P. et al. (2012). "Finding desirable orbit options for the "Extension of Life" phase of Jason-1". Mar. Geod., 35, 363Đ399.

[23] Dibarboure G., Boy F., Desjonqueres J. D., Labroue S., Lasne Y., Picot N., Poisson J. C., and Thibaut P. (2014). "Investigating ShortWavelength Correlated Errors on Low-Resolution Mode Altimetry". J. Atmos. Ocean. Technol., 31, 1337Đ1362, doi:10.1175/JTECH-D-1300081 .

[24] Dibarboure G., A. Lamy, M-I.Pujol and G. Jettou (2018). "The drifting phase of SARAL/AltiKa: Securing a stable mesoscale sampling with an unmaintained decaying altitude". Remote Sens., 10, 1051, doi:10.3390/rs10071051

[25] Durand, M., Fu, L. L., Lettenmaier, D. P., Alsdorf, D. E., Rodriguez, E., \& Esteban-Fernandez, D. (2010). The surface water and ocean topography mission: Observing terrestrial surface water and oceanic submesoscale eddies. Proceedings of the IEEE, 98(5), 766-779.

[26] Frappart, F., Papa, F., Marieu, V., Malbeteau, Y., Jordy, F., Calmant, S., ... \& Bala, S. (2015). Preliminary assessment of SARAL/AltiKa observations over the Ganges-Brahmaputra and Irrawaddy Rivers. Marine Geodesy, 38, 568-580.

[27] Gourdeau L., B. Djath, A. Ganachaud, F. Niño, F. Birol, J. Verron, N. Fuller (2017). "Altimetry in a Regional Tropical Sea: Benefits from the SARAL/AltiKa Mission". IEEE Geoscience and Remote Sensing, 5 (3), 44-52. doi:10.1109/MGRS.2017.2679484.

[28] Guerreiro, K., Fleury, S., Zakharova, E., Rémy F., and Kouraev, A. ( 2017). "Potential for estimation of snow depth on Arctic sea ice from CryoSat-2 and SARAL/AltiKa missions". Remote Sensing of Environment, 2016, 186, 339-349.

[29] Hauser, D., Tison, C., Amiot, T., Delaye, L., Corcoral, N., and Castillan, P. (2017). "SWIM: the first spaceborne wave scatterometer". IEEE Transactions on Geoscience and Remote Sensing, 55(5), 3000-3014.

[30] Hossain, F., A. H. M. Siddique-E-Akbor, L. C. Mazumdar, S. M. Shah-Newaz, S. Biancamaria, H. Lee \& C. K. Shum (2014). Proof of concept of an operational altimeter-based forecasting system for transboundary flow. IEEE Journal of Selected Topics in Applied Earth Observations and Remote Sensing, 7, 587Đ601, doi :10.1109/ JSTARS.2013.2283402.

[31] Jayles, C., Chauveau J.P., Rozo F. (2010). "DORIS/Jason-2: Better than $10 \mathrm{~cm}$ on-board orbits available for NearReal-Time Altimetry". Advance in Space Research, Vol 46, Issue 12, pp. 1497-1512, Doi: 10.1016/j.asr.2010.04.030

[32] Le Sommer, J., E.P. Chassignet, \& A.J. Wallcraft, 2018: Ocean circulation modeling for operational oceanography: Current status and future challenges. In "New Frontiers in Operational Oceanography", E. Chassignet, A. Pascual, J. Tintoré, and J. Verron, Eds., GODAE OceanView, 289-306, doi:10.17125/gov2018.ch12. 
[33] Lyard, F., F. Lefevre, T. Letellier and O. Francis (2006). "Modelling the global ocean tides: modern insights from FES2004". Ocean Dynamics, 56, 394-415.

[34] Marks, K.M. and Smith, W.H.F. (2016). "Detecting small seamounts in AltiKa repeat cycle data". Marine Geophysical Research, $37: 349$. https://doi.org/10.1007/s11001-016-9293-0

[35] Marks, K. M. and Smith, W.H.F. (2018). "A method of stacking AltiKa repeat cycle data that may reveal 75,000+ possible small seamounts". Earth and Space Science, 5, 964-969. https://doi.org/10.1029/2018EA000440

[36] Messager, M. L., Lehner, B., Grill, G., Nedeva, I., \& Schmitt, O. (2016). Estimating the volume and age of water stored in global lakes using a geo-statistical approach. Nature communications, 7, 13603.

[37] Nouguier, F., Mouche, A., Rascle, N., Chapron, B., and Vandemark, D. (2016). "Analysis of dual-frequency ocean backscatter measurements at Ku-and Ka-bands using near-nadir incidence GPM radar data". IEEE Geoscience and Remote Sensing Letters, 2016, 13(9), $1310-1314$.

[38] Peacock N. and Laxon S. (2004)."Sea Surface Height Determination in the Arctic Ocean from ERS Altimetry". Journal of Geophysical Research: Oceans, Vol.109, C07001, doi:10.1029/2001JC001026.

[39] Quartly G. and M.Passaro (2018). "Initial Examination of AltiKa's Individual Echoes". Marine Geodesy, 38, 73-85, doi: $10.1080 / 01490419.2014 .984882$

[40] Ray R. D. (2013). Precise comparisons of bottom-pressure and altimetric ocean tides, J. Geophys. Res., 118, 4570-4584

[41] Ray R. \& E. D. Zaron, (2016). M2 internal tides and their observed wavenumber spectra from satellite altimetry. J. Phys. Oceanogr., 46(1):322

[42] Roca M., D. Martinez and M. Reche, (2007). "The RA-2 Individual Echoes Processing Description and some Scientific Results". IEEE International Geoscience and Remote Sensing Symposium, Barcelona, pp. 3541-3546. doi: 10.1109/IGARSS.2007.4423610

[43] Rodriguez E. (2015). "Surface Water and Ocean Topography project, science requirement document". release February 2015, JPL D-61923

[44] Sandwell, D. T., Müller, R. D., Smith, W. H., Garcia, E., and Francis, R. (2014). "New global marine gravity model from CryoSat-2 and Jason-1 reveals buried tectonic structure". Science, 346(6205), 65-67.

[45] Screen, J. A., \& Simmonds, I. (2010). The central role of diminishing sea ice in recent Arctic temperature amplification. Nature, 464(7293), 1334.

[46] Smith, W. H. F. (2015). "The Resolution of Seamount Geoid Anomalies Achieved by the SARAL/AltiKa and Envisat RA2 Satellite Radar Altimeters". Marine Geodesy, 38(S1), 644-671.

[47] Stammer, D., R. D. Ray, O. B. Andersen, et al, (2014). Accuracy assessment of global barotropic ocean tide models." Rev. Geophys., 52: 243-282

[48] Steunou N., J. D. Desjonquères, N. Picot, P. Sengenes, J. Noubel and J. C. Poisson (2015). "AltiKa Altimeter: Instrument Description and In Flight Performance". Marine Geodesy, 38, 22-42.

[49] Schwatke, C., Dettmering, D., Börgens, E., \& Bosch, W. (2015). Potential of SARAL/AltiKa for inland water applications. Marine Geodesy, $38,626-643$

[50] Tourian, M.J.; Tarpanelli, A.; Elmi, O.; Qin, T.; Brocca, L.; Moramarco, T.; Sneeuw, N. (2016). Spatiotemporal 728 densification of river water level time series by multimission satellite altimetry. Water Resour. Res., 52, 729 1140-1159, doi:10.1002/2015WR017654.

[51] Tournadre, J., Lambin-Artru, J., \& Steunou, N. (2009). "Cloud and rain effects on ALTIKA/SARAL Ka-band radar altimeterÑPart II: Definition of a rain/cloud flag". IEEE Transactions on Geoscience and Remote Sensing, 47(6), 1818-1826.

[52] Tournadre J., J. C. Poisson, N. Steunou \& B. Picard (2015) Validation of AltiKa Matching Pursuit Rain Flag, Marine Geodesy, 38:sup1, 107-123, DOI: 10.1080/01490419.2014.1001048

[53] Vergara O., Morrow R., Pujol I., Dibarboure G. and Ubelmann C. (2019). "Revised global wavenumber spectra from recent altimeter observations". J. Geophys. Res., doi: 10.1029/2018JC014844

[54] Verpoorter, C, T. Kutser, D. A. Seekell, and L. J. Tranvik (2014). A global inventory of lakes based on high-resolution satellite imagery, Geophys. Res. Lett, 41,6396Đ6402, doi:10.1002/2014GL060641.

[55] Verron J. and N. Picot (Eds), (2015). "The SARAL/AltiKa Satellite Altimetry Mission". Marine Geodesy 2015, 38 (S1).

[56] Verron J., P. Bonnefond, L. Aouf, F. Birol, S. A. Bhowmick, S. Calmant, T. Conchy, J. F. Crétaux, G. Dibarboure, A. K. Dubey, Y. Faugère, K. Guerreiro, P. K. Gupta, M. Hamon, F. Jebri, R. Kumar, R. Morrow, A. Pascual, M. I. Pujol, E. Rémy, F. Rémy, W.H. F. Smith, J. Tournadre and O. Vergara (2018). "The Benefits of the Ka-Band as Evidenced from the SARAL/AltiKa Altimetric Mission: Scientific Applications". Remote Sens., 10(2), 163. doi:10.3390/rs10020163

[57] Xie, J., Counillon, F., and Bertino, L. (2018). "Impact of assimilating a merged sea-ice thickness from CryoSat-2 and SMOS in the Arctic reanalysis". The Cryosphere, 12(11), 3671-3691.

[58] Zhang, S., and Sandwell, D. T. (2017). "Retracking of ALTIKA/AltiKa radar altimetry waveforms for optimal gravity field recovery". Marine Geodesy, 40(1), 40-56.

\section{Acknowledgements}

The contributions of A. Abulatitijiang, S. Bruinsma, H. Harper, J. Le Sommer, F. Lyard \& R. Morrow are deeply acknowledged. This work was sponsored by CNES as part of the TOSCA program. Ocean Next contribution is for a part supported by CNES and CMEMS. Thanks to CNES and ISRO for having adapted their plan of operations in order to acquire the useful dataset of SARAL/AltiKa over the Salar de Uyuni. The sea ice thickness and snow depth studies have also been supported by the Cryo-SeaNice ESA project and the data base is available at LEGOS/CTOH. 
Wavelength $(\mathrm{km})$

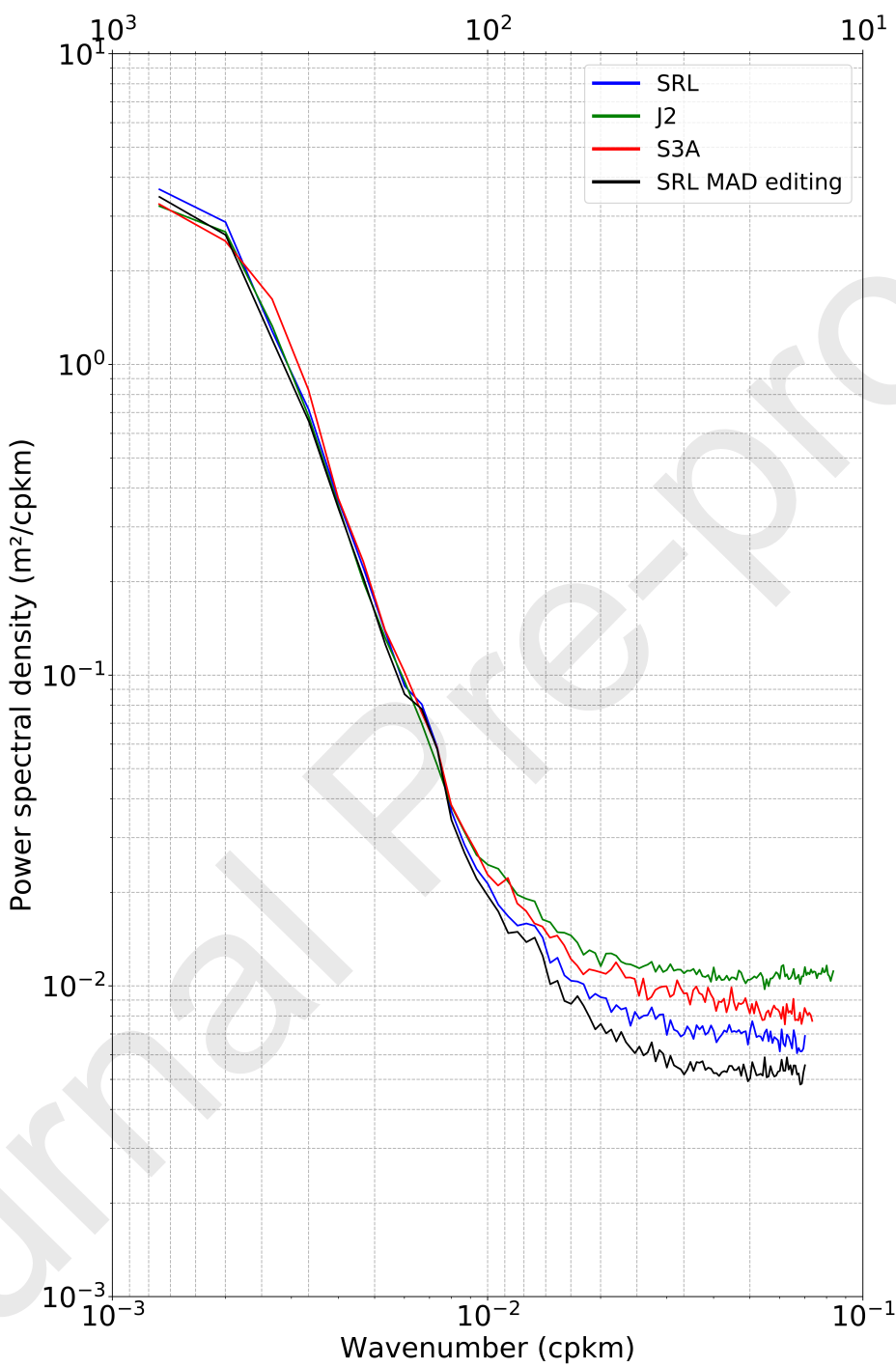

FIGURE 1: Wavenumber spectra of SSH anomalies (in $\mathrm{m}^{2} / \mathrm{cpkm}$ ) from the $1 \mathrm{~Hz}$ along-track data representative of a $1500 \mathrm{~km} \times 1500 \mathrm{~km}$ box located southeast of New Caledonia $\left(34^{\circ}-20^{\circ} \mathrm{S} ; 168^{\circ}-180^{\circ} \mathrm{E}\right)$ for three different missions: Jason-2 (J2 in green); Sentinel-3A (S3A in red); and SARAL/AltiKa (SRL in blue) when using the standard editing procedure recommended in the User Handbook. SARAL/AltiKa is particularly sensitive to the editing criteria, and applying an additional MAD filter on the along track data modifies greatly the shape of the SARAL/AltiKa spectrum for wavelengths shorter than $90 \mathrm{~km}$ (SRL in black). 


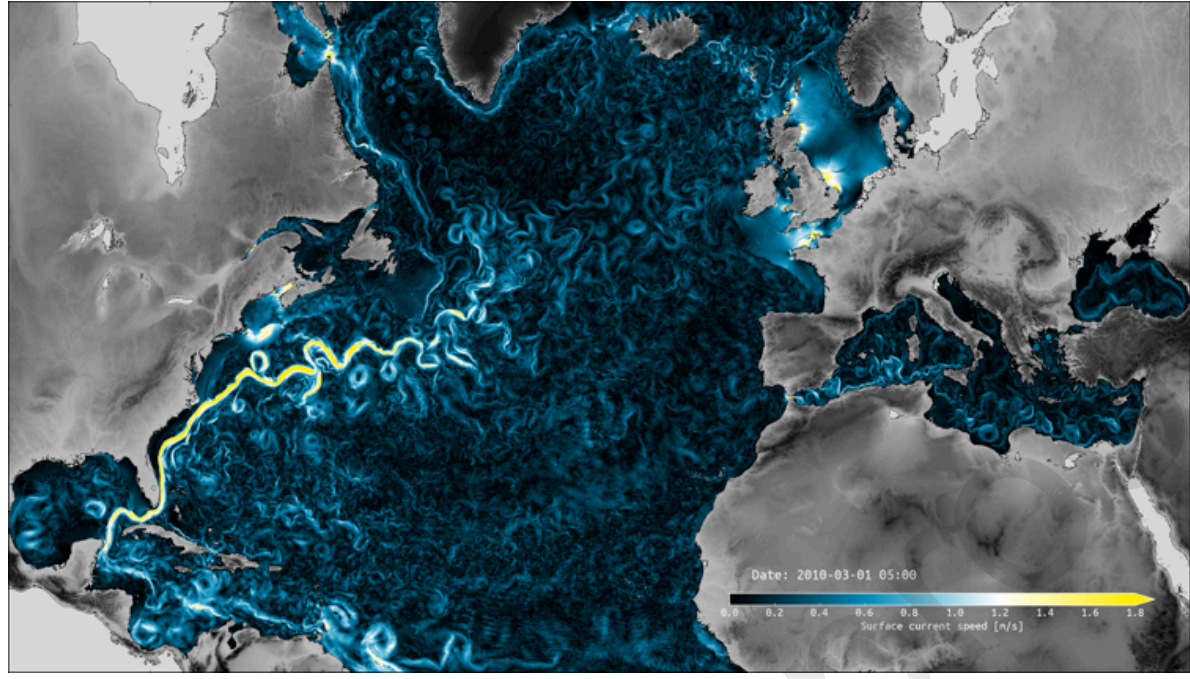

FIGURE 2: Geographical domain eNATL60, instantaneous speed of the current in the simulation with explicit resolution of the tide.

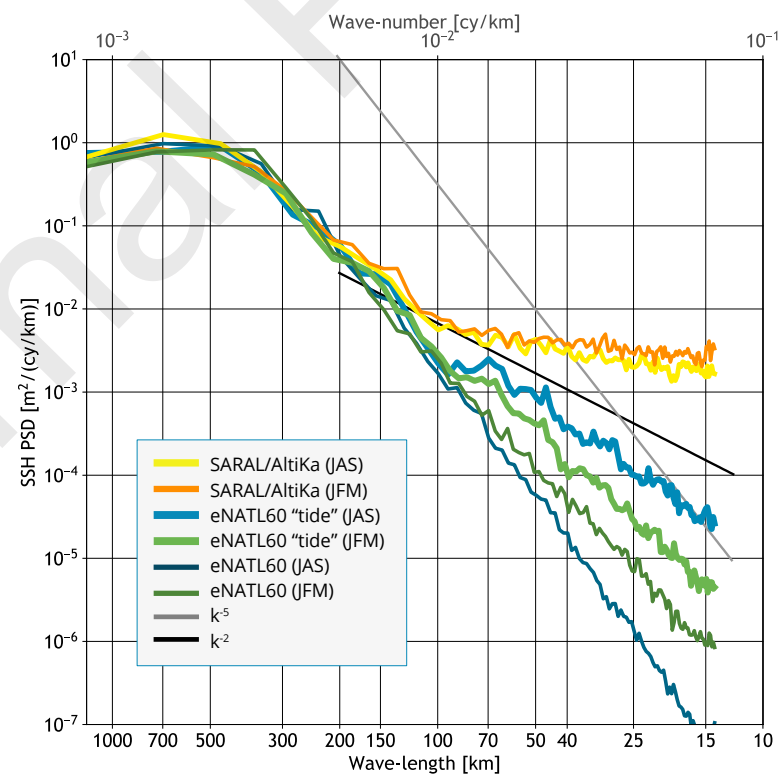

FIGURE 3: SSH Power Spectrum during Summer 2016 (July, August, September, JAS) and Winter 2017 (January, February, March, JFM) over a region of the North Atlantic centered southwest of the Azores ( 37 to $24^{\circ} \mathrm{W}$ and 23 to $40^{\circ} \mathrm{N}$ ) (i) as observed by SARAL/AltiKa, and (ii) based on the hourly SSH of eNATL60 (with and without explicit resolution of the tide) interpolated in space and time on SARAL/AltiKa's ground track. 


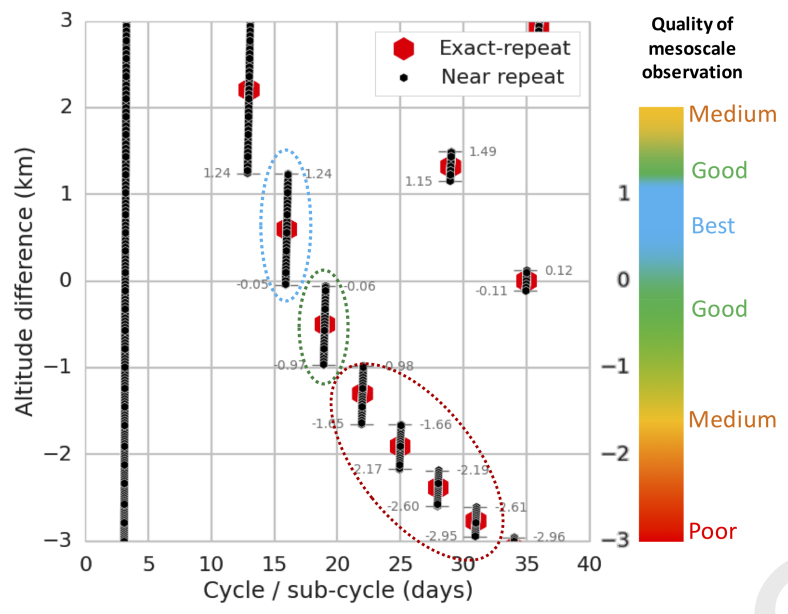

FIGURE 4: Overview of the dominant sub-cycles for a 6-km altitude range near the historical ERS orbit. The quality of mesoscale observation is controlled by some sub-cycles ( 15 to 19 days is better) so some altitude ranges are better than others (colored ellipses and right-hand-side color bar). From Dibarboure et al. (2018).
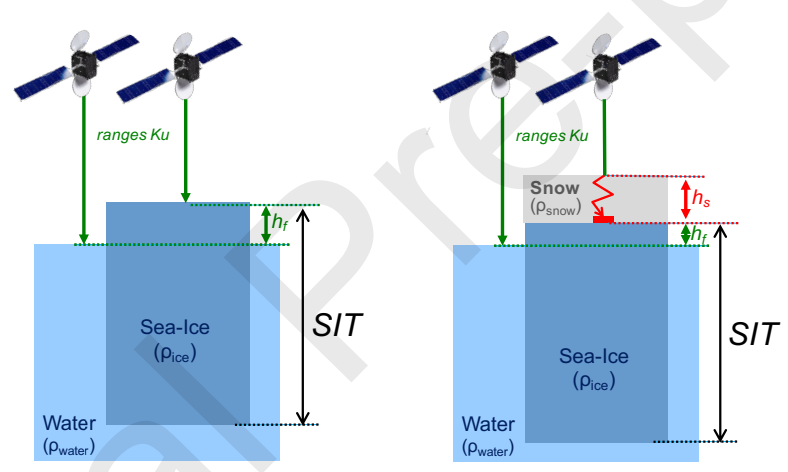

FiguRE 5: These diagrams illustrate the principle of measuring the sea ice thickness by altimetry, without snow on the left, and with snow on the right. The snow sinks the ice on the water and slows down the radar speed propagation. These two effects reduce the perceptible freeboard of the ice and must be taken into account to retrieve the real sea ice thickness.
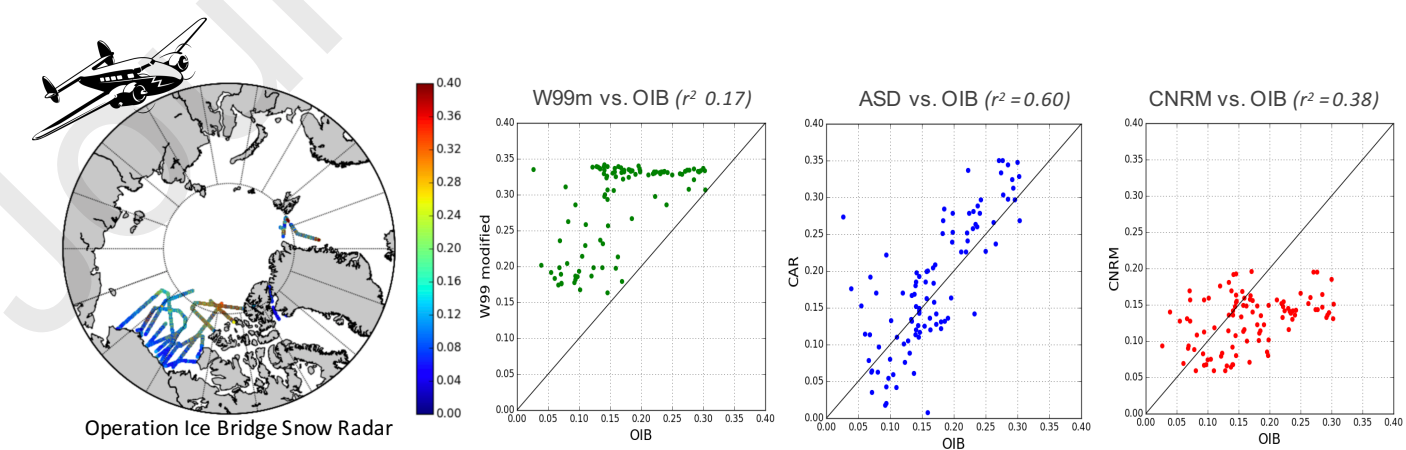

FIGURE 6: Snow depth measurements using Operation Ice Bridge airborne snow radar (left map), compared with, left to right scatter plots, the Warren 99 snow depth modified climatology, the Altimetry Snow Depth (ASD) solution, and the CNRM-CMIP5 model forced by ERA-Interim reanalysis. We can observe that W99m remains too high, despite the heuristic correction over the first year ice. The low CNRM values are due to too low ERA-Interim precipitation, which highlights the lack of observation over this region. 


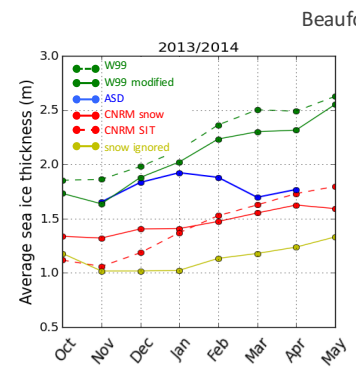

Beaufort Sea

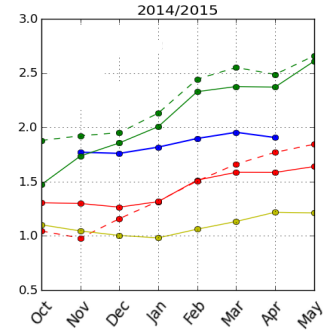

Pan-Arctic up to $81.5^{\circ} \mathrm{N}$
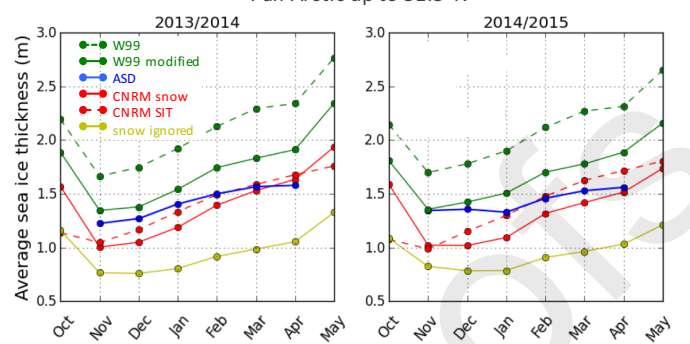

Figure 7: Average altimetric Sea Ice Thickness for the winters 2013/14 and 2014/15 over the Beaufort Sea (left plots) and over the Arctic Basin (right plots) up to $81.5^{\circ} \mathrm{N}$. The Beaufort Sea is the region where the altimetric freeboard and snow depth have been validated with OIB (see Figure 6). The different color curves correspond to different snow depth estimations. The extreme curves were respectively obtained with the Warren climatology (green dotted lines) and a solution ignoring the snow (yellow line). The reality is probably in-between the solution using the Modified Warren climatology (green lines), that provides over estimated SD, and the solution using the CNRM-CMIP5 model (red lines), that provides under estimated SD, i.e., a discrepancy of $0.5 \mathrm{~m}$ for a mean SIT of $1.5 \mathrm{~m}$. The solution using Alti Snow Depth is in blue.

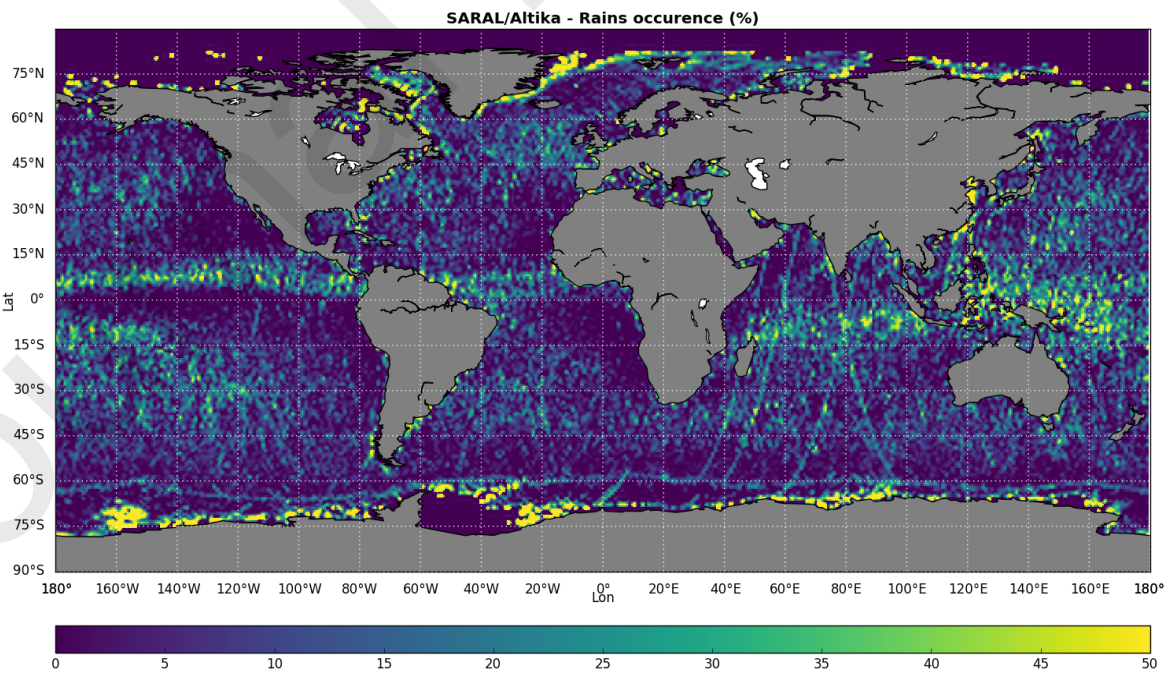

FIGURE 8: Percentage of measurements impacted by rain events on SARAL/AltiKa. 


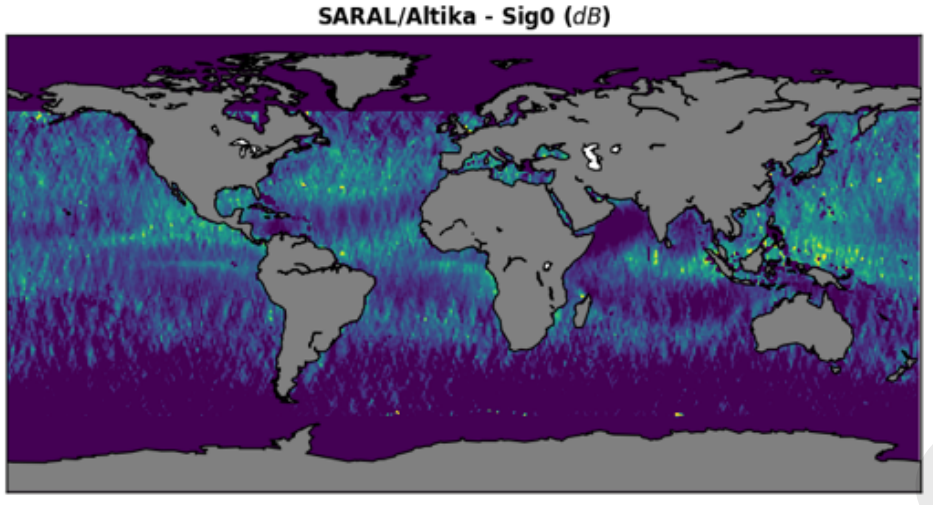

Lon

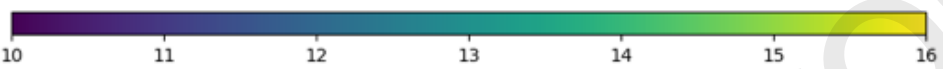

a)

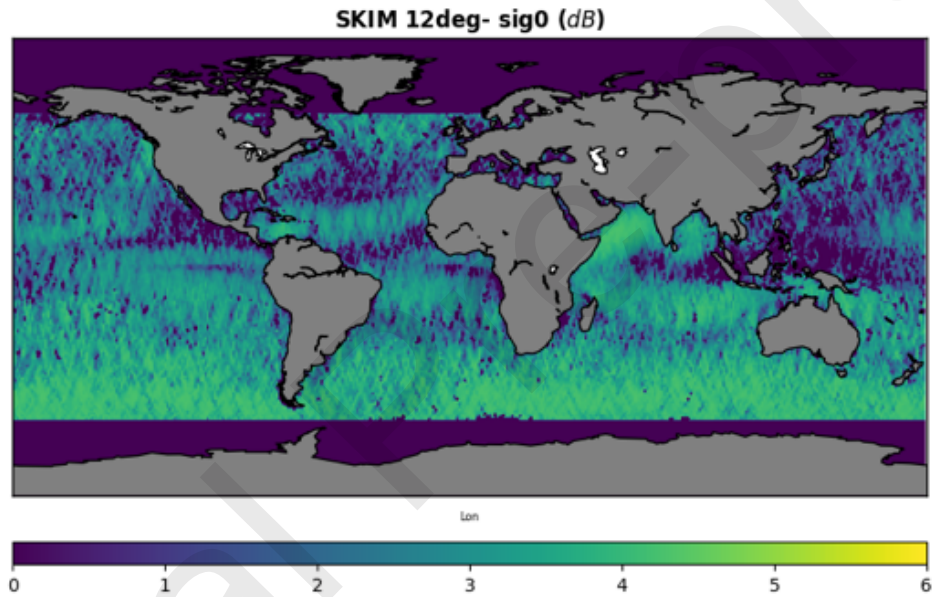

b)

SKIM 12deg- 1/sig0 dsig0/dx (RMS, 1/km)

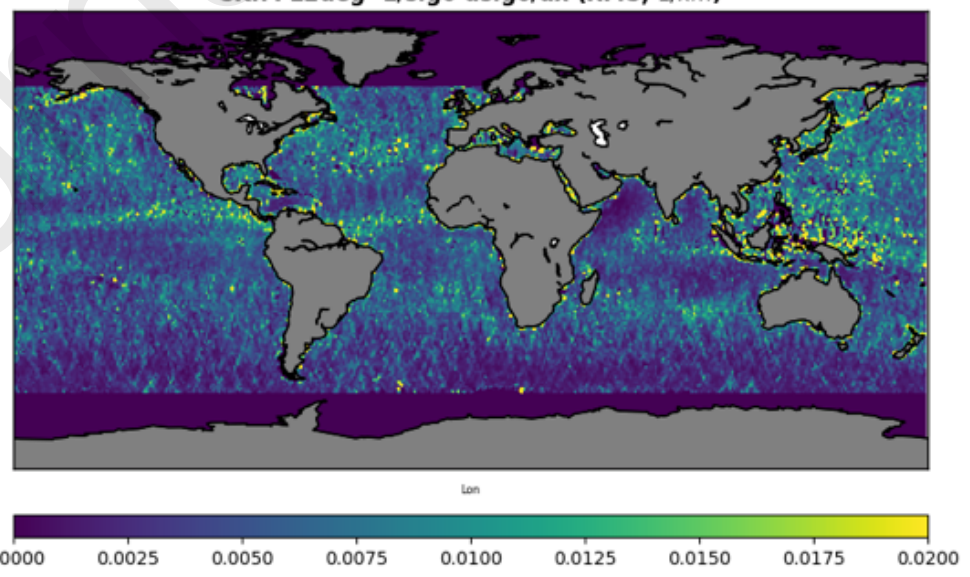

c)

FIGURE 9: (a) SARAL/AltiKa $\sigma_{0}$ map (dB), (b) SKIM $\sigma_{0}$ map (dB, at $12^{\circ}$ incidence, extrapolated from SARAL/AltiKa), (c) SKIM $\sigma_{0}$ gradients $(\mathrm{dB} / \mathrm{km})$. 


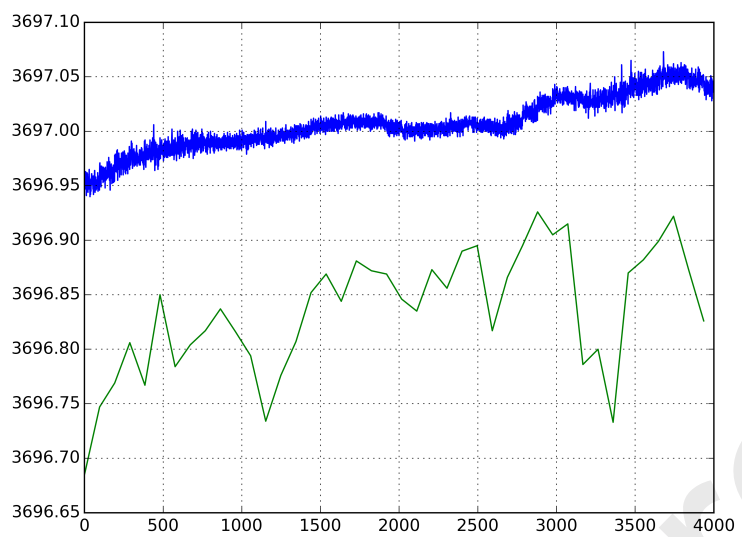

FigURE 10: Retrieved height (WGS84) of the inundated Salar de Uyuni water surface in meters: computed from the SARAL/AltiKa IE (blue), computed from the $40 \mathrm{~Hz}$ echoes in the SGDR with ice1 retracking (green).The absolute value and the bias between the two curves is not significant and has been adjusted to make the figure clear.

SARAL/AItiKa

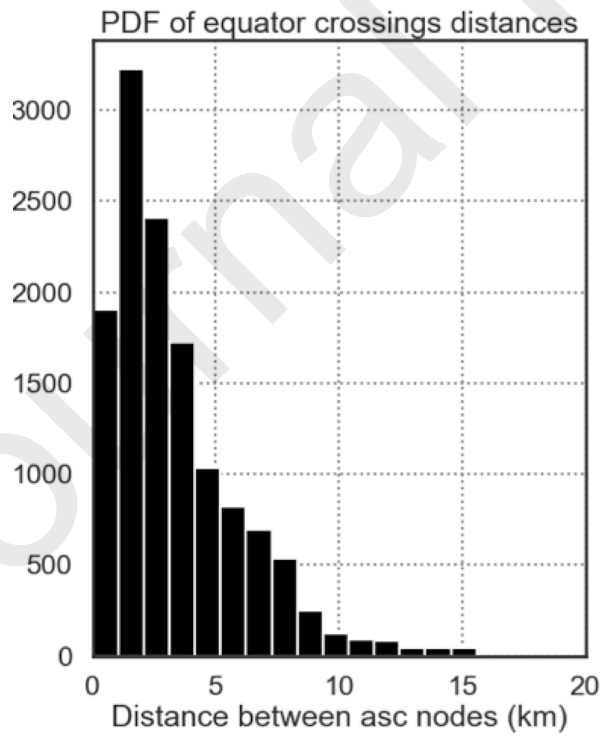

Jason-2 LRO

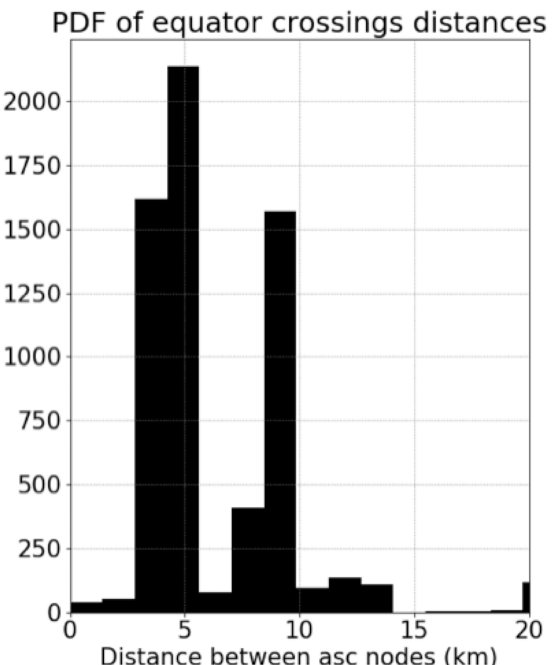

FIGURE 11: Histogram of the distance between the adjoining equator crossings (ascending tracls) of the geodetic grids of SARAL-DP (panel a) and Jason-2 LRO (panel b) in January 2019. 


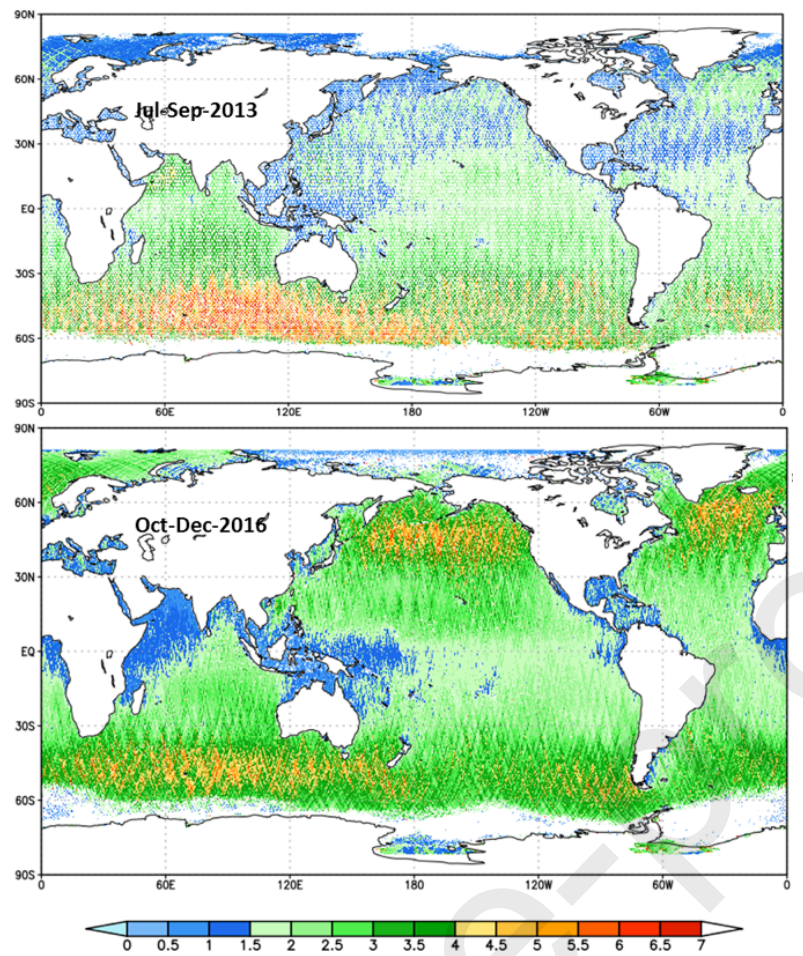

FIGURE 12: The 3 monthly average of SWH data from ERM and GM modes
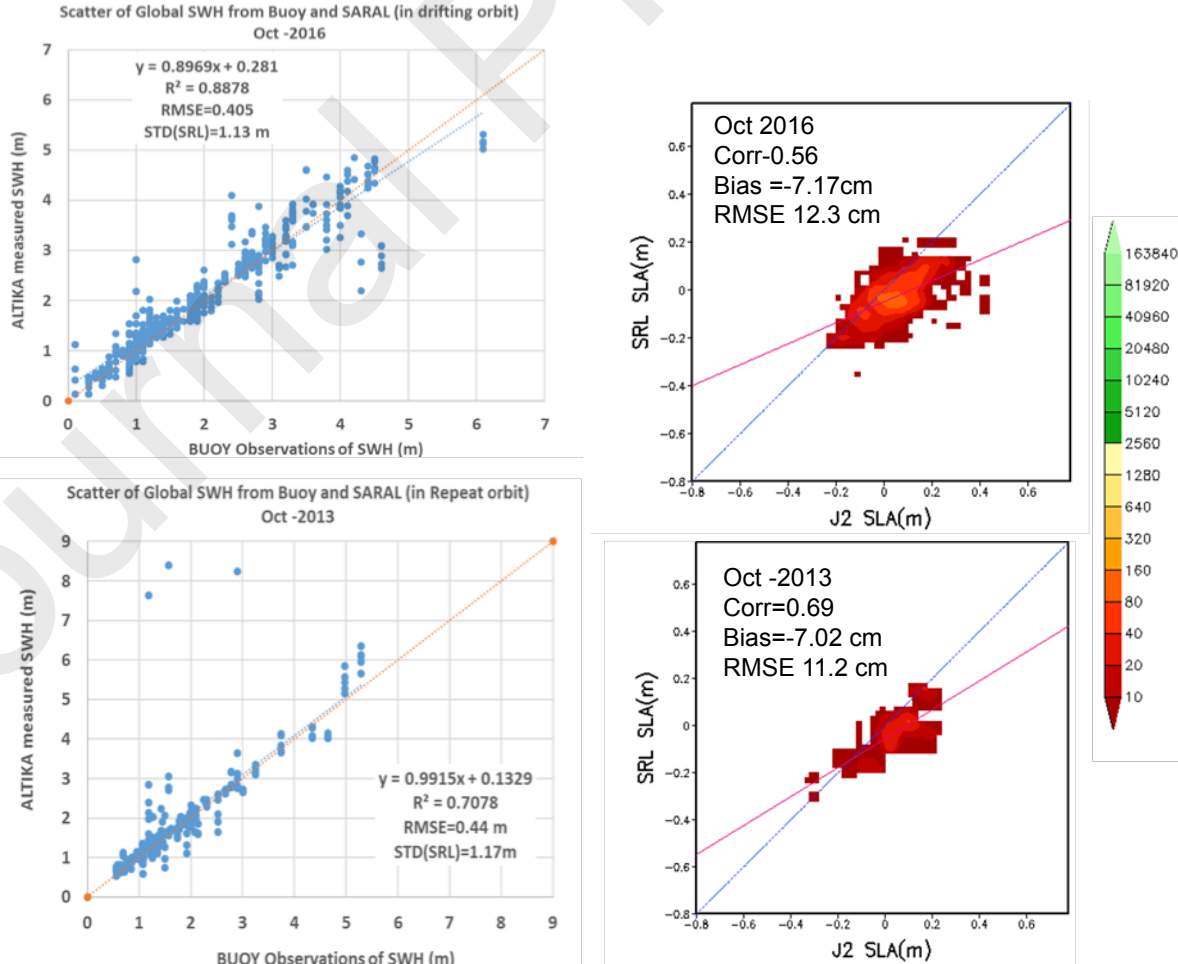

FIGURE 13: (Left panel) The Validation of SWH for Octobers of 2013 and 2016 using global buoy observations. (Right Panel) The inter comparison of SLA from Jason-2 and SARAL for the same period as SWH. 

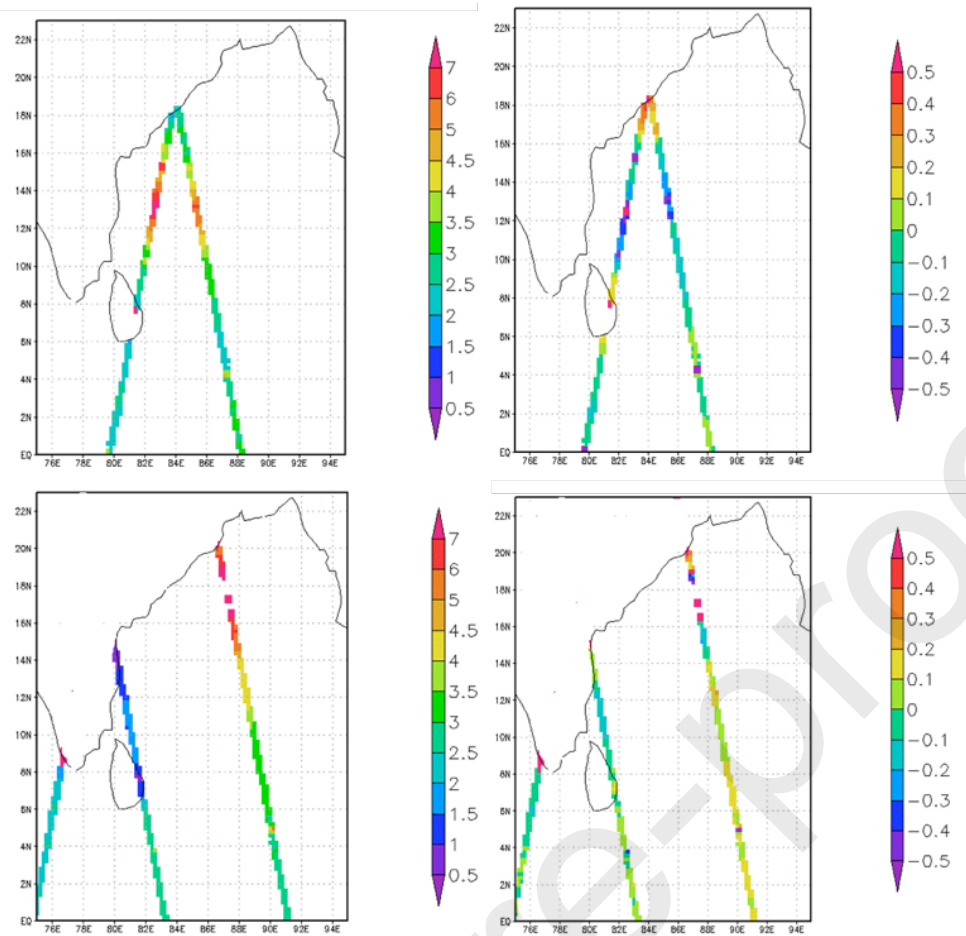

FIGURE 14: SARAL/AltiKa observing wave height and SSHA during Phailin and Vardah on 11th October 2013 and 11th December 2016 respectively. In these dates the Cyclones were at its peak intensity.

01 Dec 2016 (Before Vardah )

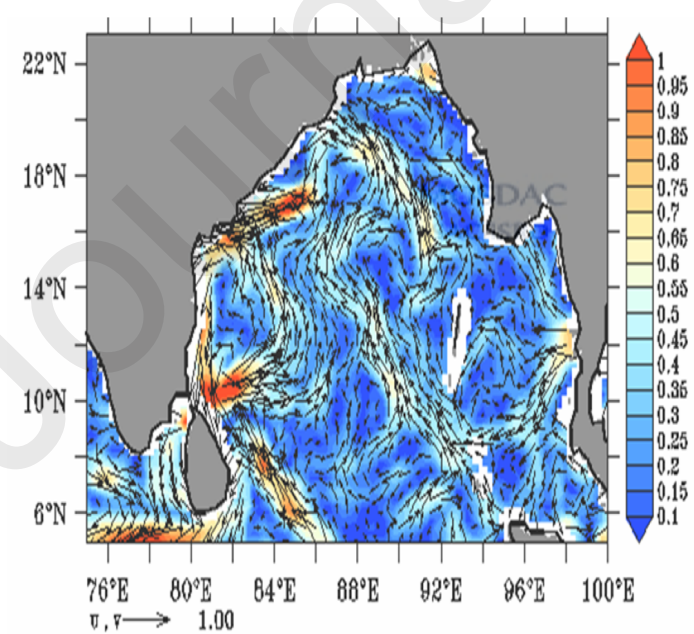

11 Dec 2016 (Vardah at its peak intensity)

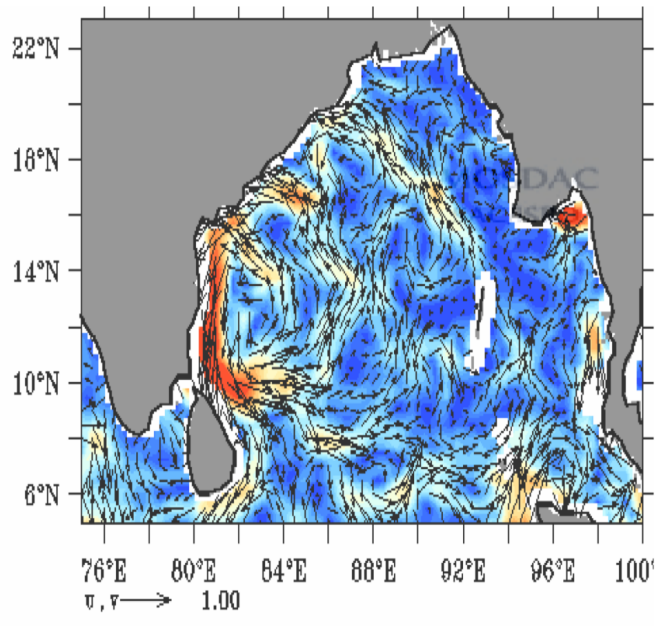

FIGURE 15: East Indian Coastal Current before (left) and during (right) Vardah. 


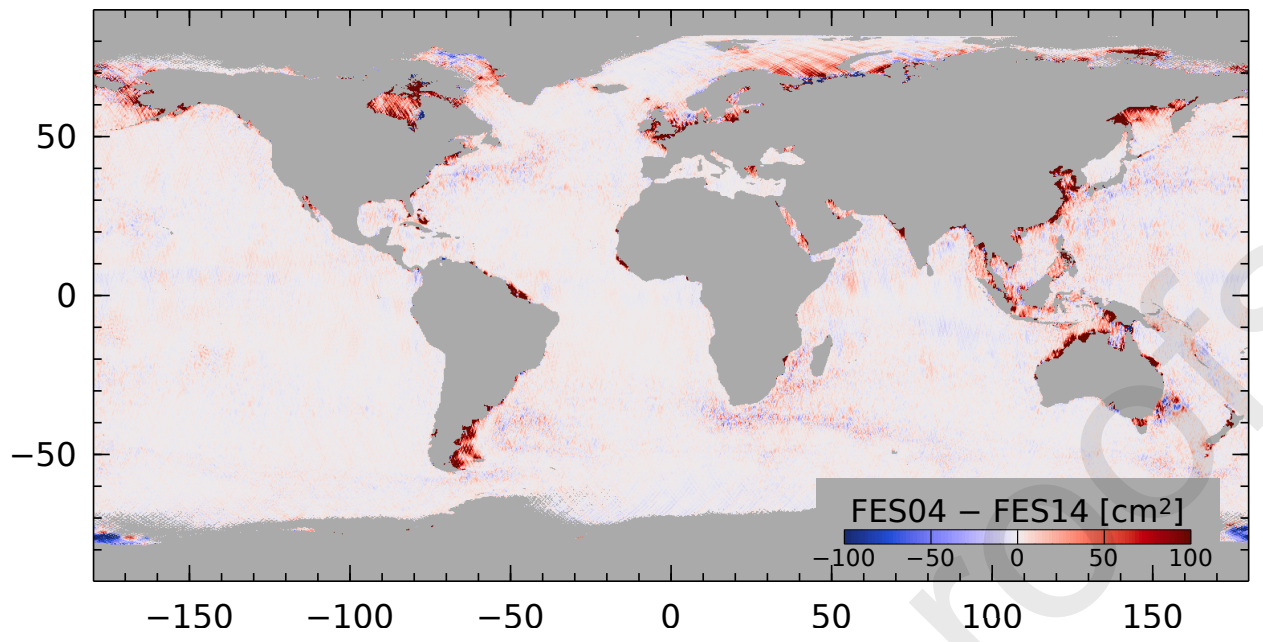

FIGURE 16: Evaluating tide models with SARAL/AltiKa data from the drifting orbit phase (July 2016-June 2019). SARAL/AltiKa provides an important source of precise SLA at locations off the reference mission ground tracks. It permits the validation of tide models in coastal regions where the scales of the tide are comparable to, or smaller than the resolution of the reference missions. Regions in red, generally near the coast, show where the newer tide model (FES2014) explains more SLA variance than the old tide model (FES2004).

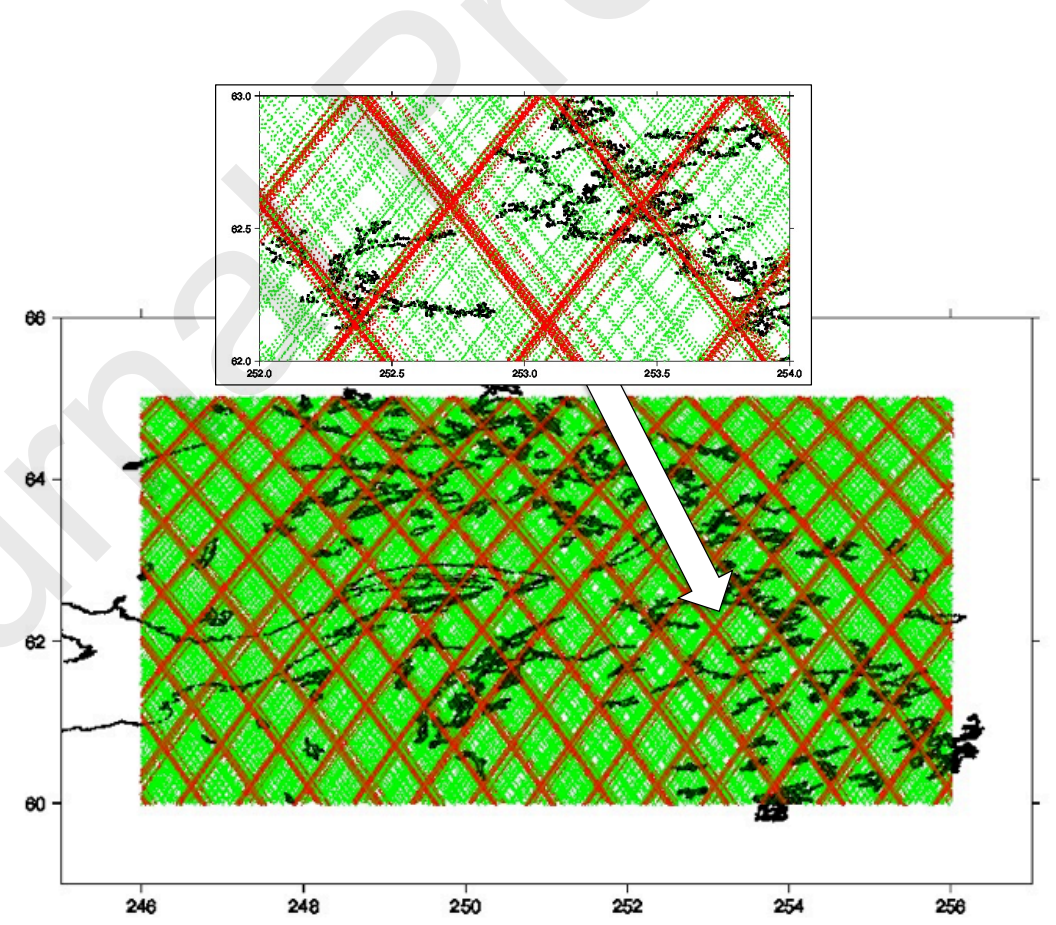

FIGURE 17: Projection of the SARAL/AltiKa tracks over the region located on the East of the Hudson bay in Canada (with a zoom for a better view of the detailed tracking coverage). Red line represents the nominal orbit, green light the Drifting Phase from cycle 100 to cycle 126 . The contour of lakes are inferred from the GLWD database. 

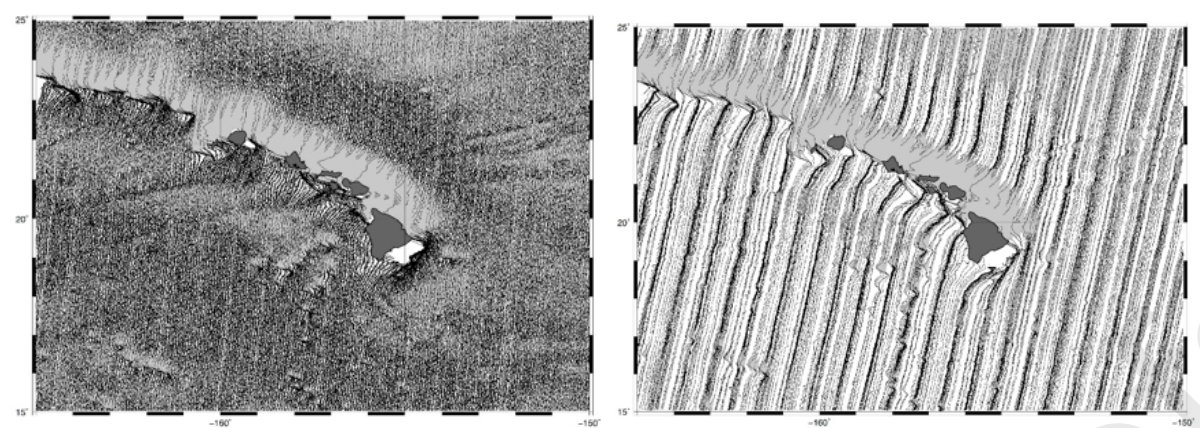

FigURE 18: 77 months of Cryosat sea surface slopes around Hawaii (left) and 13 months of SARAL/AltiKa sea surface slopes (right). The varying ground track density is clearly shown.

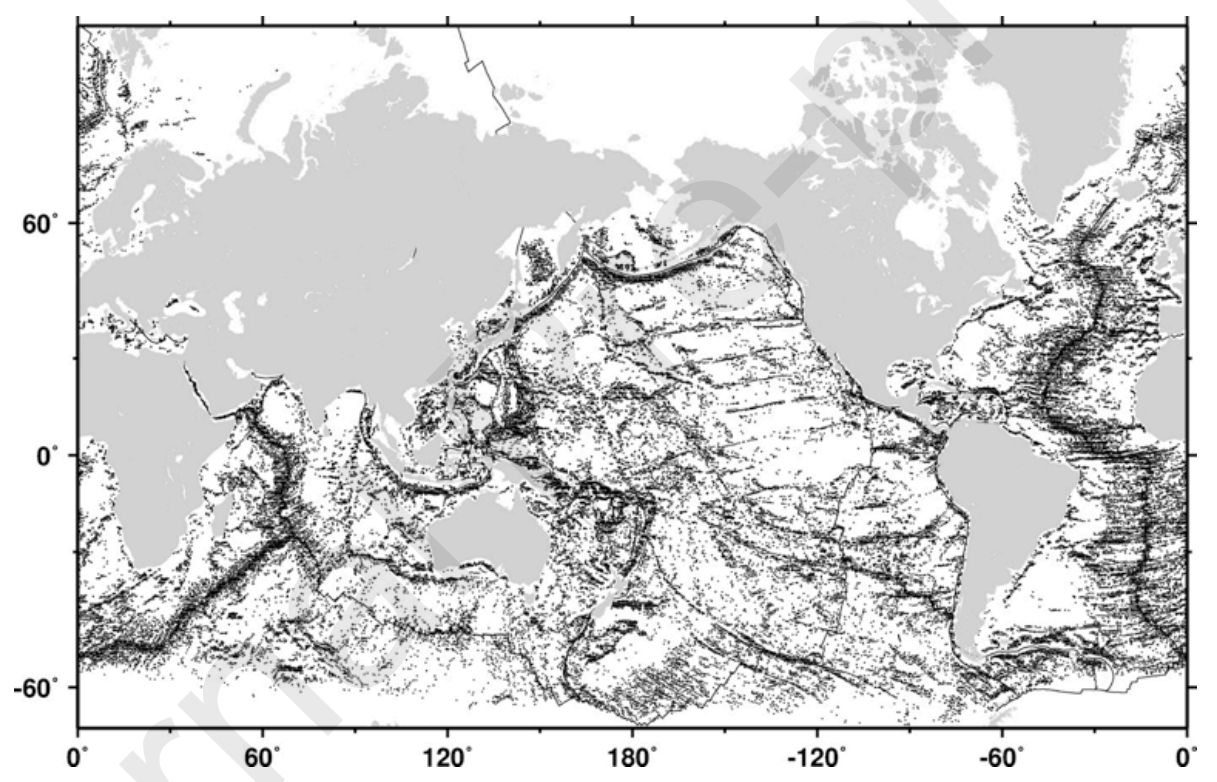

FiguRE 19: Locations of possible seamounts detected in AltiKa repeat cycles (from Fig. 4 in (Marks \& Smith 2018)).

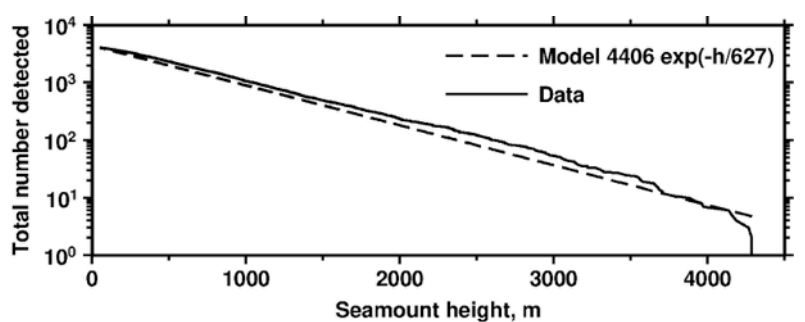

FIGURE 20: Cumulative number of possible seamounts located over multibeam surveys versus estimated seamount height (from Fig. 5, (Marks \& Smith 2018)). 


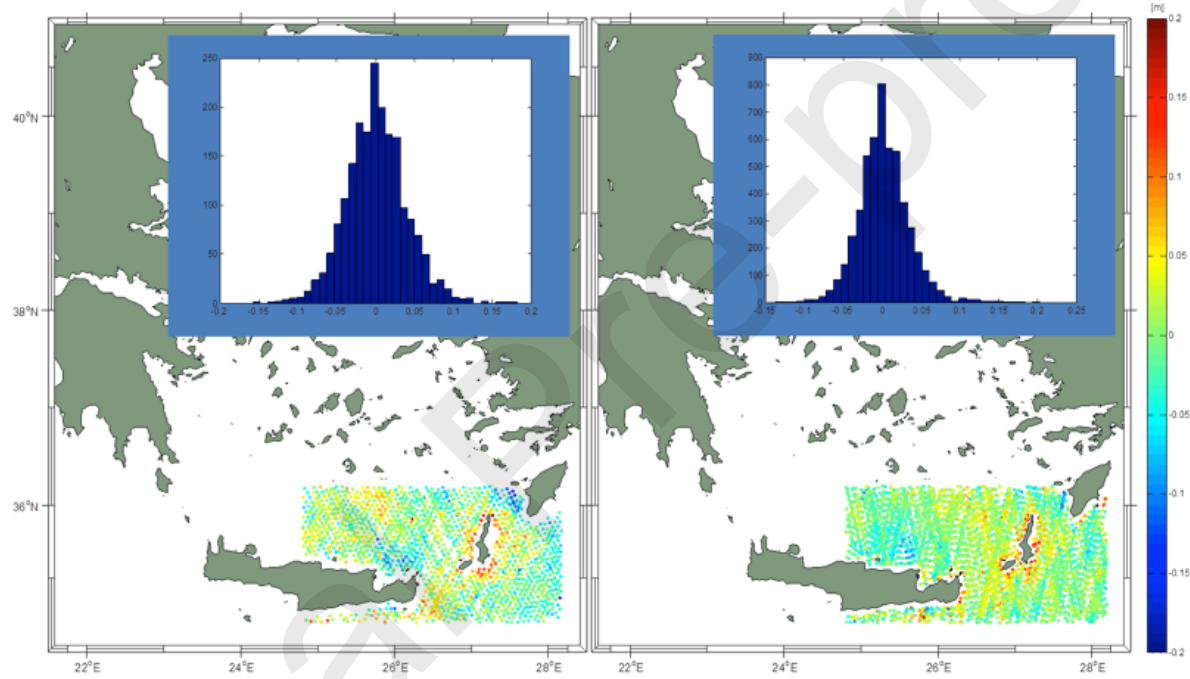

FIGURE 21: Residual geoid heights in meters from Jason-1 (left) and SARAL/AltiKa (right) close to Crete (Eastern Mediterranean Sea). The histogram of residuals (in meters) is shown as well. SARAL/AltiKa clearly shows superior data-coverage and a narrower histogram compared with Jason-1 being very valuable to coastal geodesy. 


\section{Declaration of interests}

$\bigotimes$ The authors declare that they have no known competing financial interests or personal relationships that could have appeared to influence the work reported in this paper.

$\square$ The authors declare the following financial interests/personal relationships which may be considered as potential competing interests:

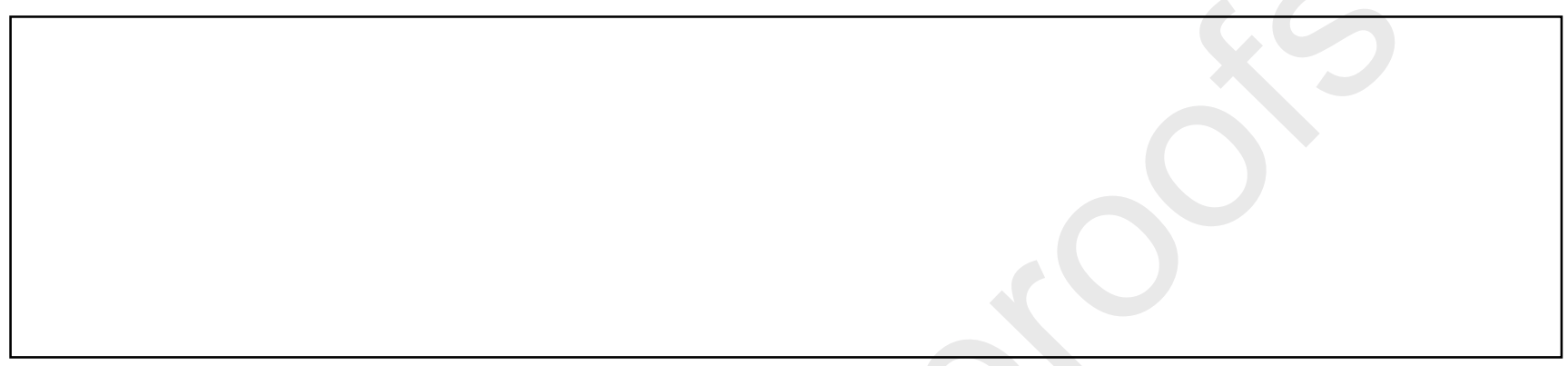

